\title{
Sensitivity and Uncertainty of the IFR-1 BISON Benchmark
}

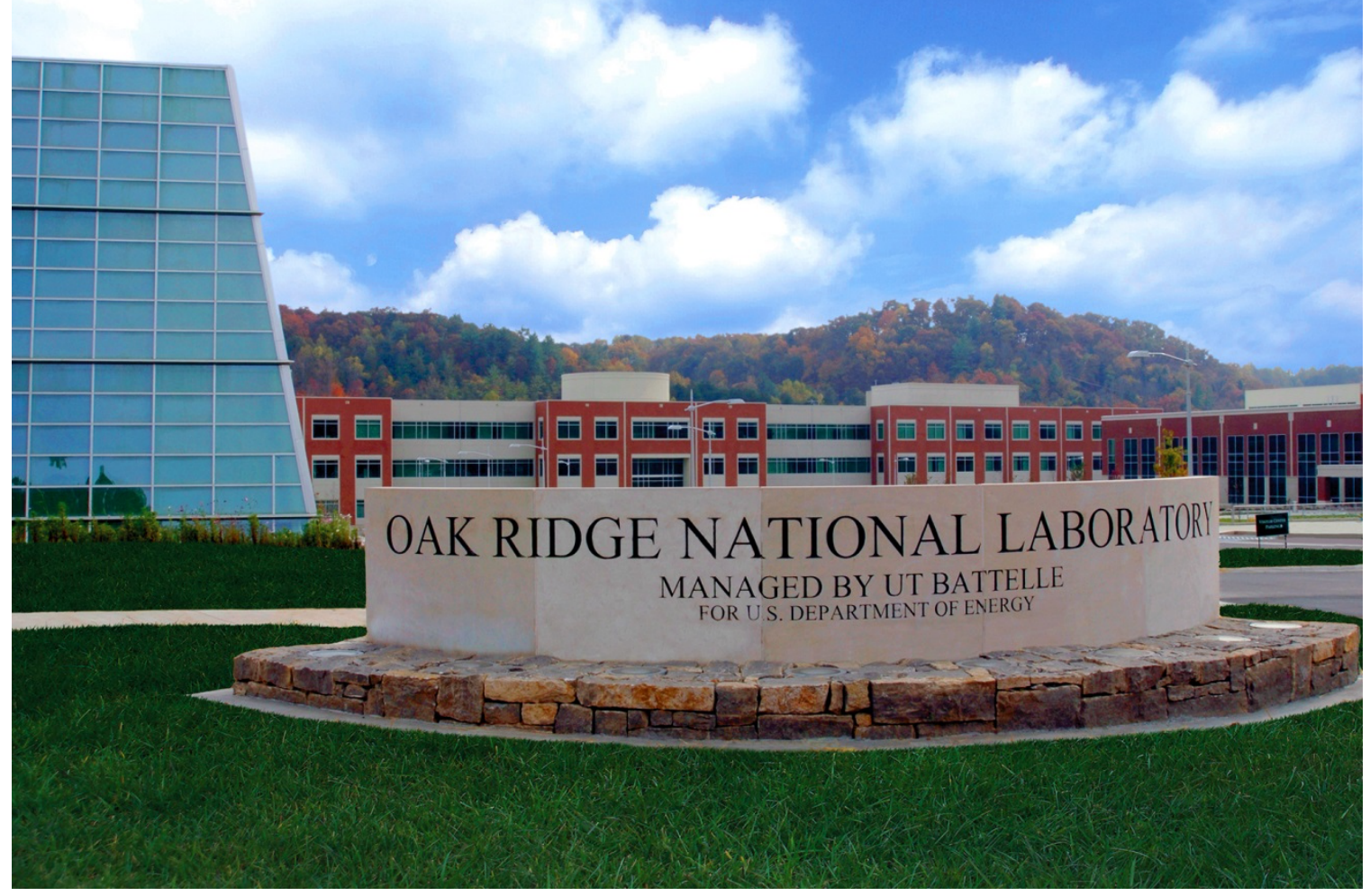

lan Greenquist

Jeffrey J. Powers

November 2021

Approved for public release.

Distribution is unlimited.

\section{OAK RIDGE




\title{
DOCUMENT AVAILABILITY
}

Reports produced after January 1, 1996, are generally available free via US Department of Energy (DOE) SciTech Connect.

Website www.osti.gov

Reports produced before January 1, 1996, may be purchased by members of the public from the following source:

\author{
National Technical Information Service \\ 5285 Port Royal Road \\ Springfield, VA 22161 \\ Telephone 703-605-6000 (1-800-553-6847) \\ TDD 703-487-4639 \\ Fax 703-605-6900 \\ E-mail info@ntis.gov \\ Website http://classic.ntis.gov/
}

Reports are available to DOE employees, DOE contractors, Energy Technology Data Exchange representatives, and International Nuclear Information System representatives from the following source:

Office of Scientific and Technical Information

PO Box 62

Oak Ridge, TN 37831

Telephone 865-576-8401

Fax 865-576-5728

E-mail reports@osti.gov

Website https://www.osti.gov/

This report was prepared as an account of work sponsored by an agency of the United States Government. Neither the United States Government nor any agency thereof, nor any of their employees, makes any warranty, express or implied, or assumes any legal liability or responsibility for the accuracy, completeness, or usefulness of any information, apparatus, product, or process disclosed, or represents that its use would not infringe privately owned rights. Reference herein to any specific commercial product, process, or service by trade name, trademark, manufacturer, or otherwise, does not necessarily constitute or imply its endorsement, recommendation, or favoring by the United States Government or any agency thereof. The views and opinions of authors expressed herein do not necessarily state or reflect those of the United States Government or any agency thereof. 
Nuclear Energy and Fuel Cycle Division

SENSITIVITY AND UNCERTAINTY OF THE IFR-1 BISON BENCHMARK

Ian Greenquist

Jeffrey J. Powers

November 2021

Prepared by OAK RIDGE NATIONAL LABORATORY

Oak Ridge, TN 37831-6283

managed by

UT-BATTELLE LLC

for the

US DEPARTMENT OF ENERGY

under contract DE-AC05-00OR22725 



\section{CONTENTS}

CONTENTS............................................................................................................ii

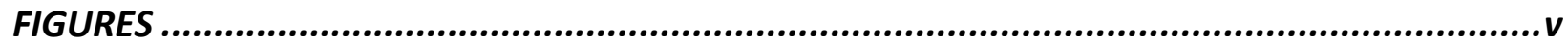

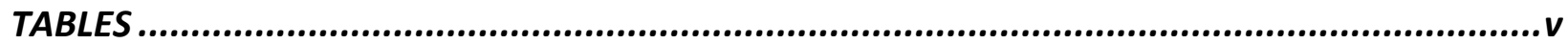

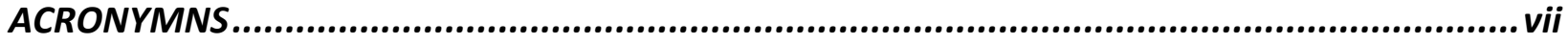

ACKNOWLEDGMENTS............................................................................................. vii

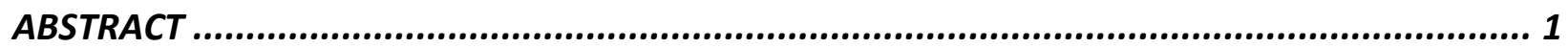

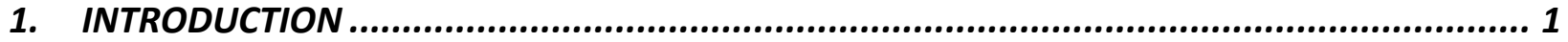

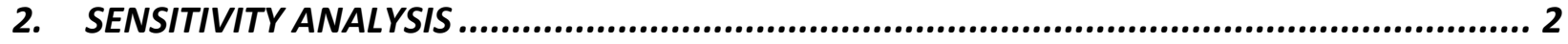

$2.1 \quad$ INPUT SELECTION

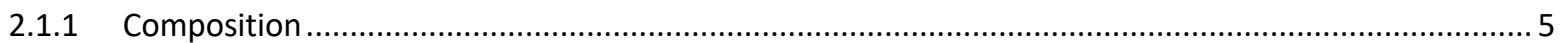

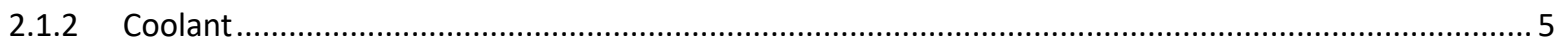

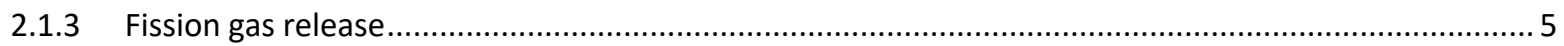

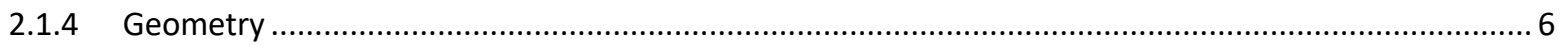

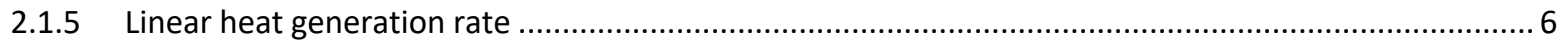

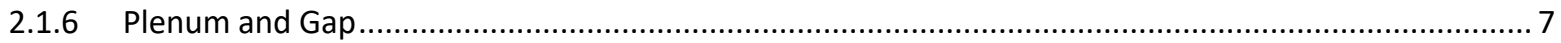

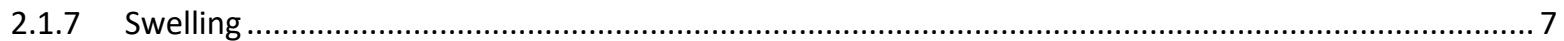

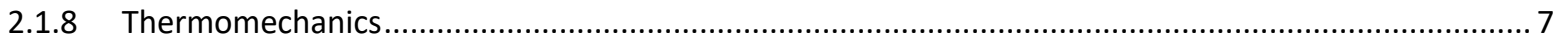

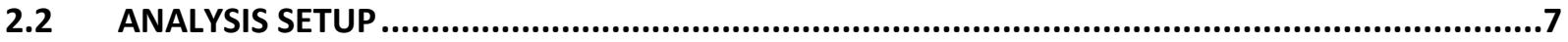

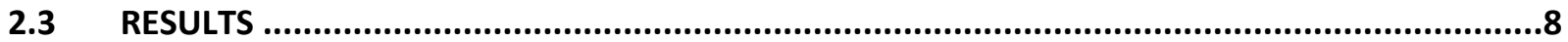

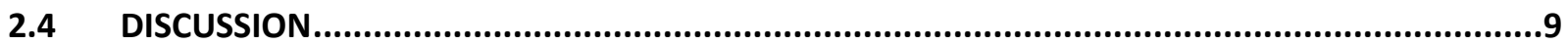

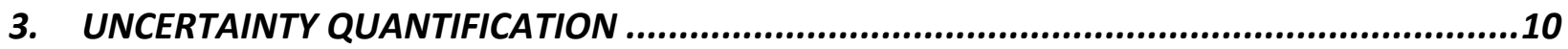

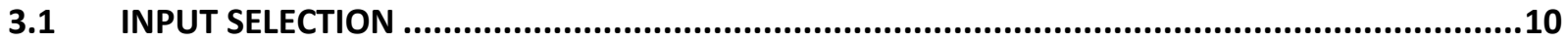

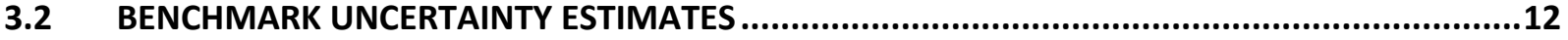

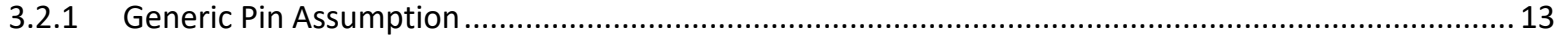

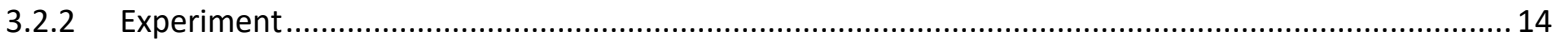

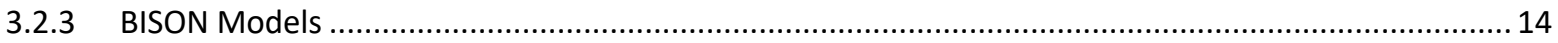

$3.3 \quad$ LEGACY CONFIDENCE INTERVAL ESTIMATES ................................................................15

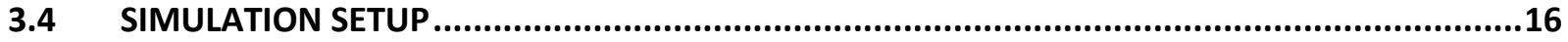

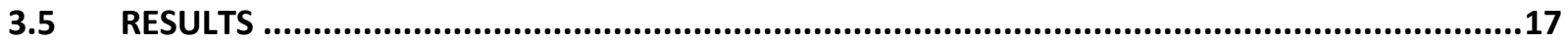

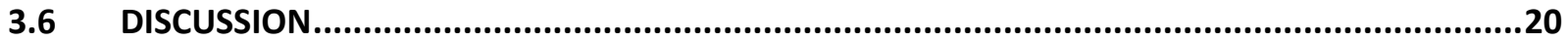

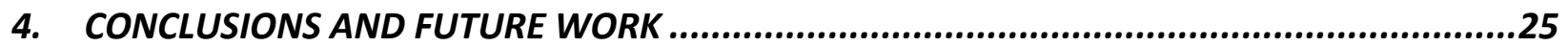

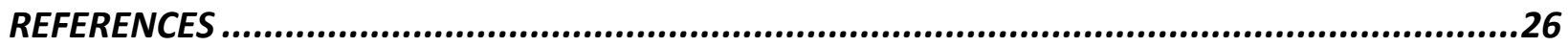




\section{FIGURES}

Figure 1. Benchmark predictions plotted and corresponding legacy values for all legacy values and all compositions...

Figure 2. Uncertainty distribution for the eight benchmark predictions for the $00 \mathrm{Pu}$ case.

Figure 3. Uncertainty distribution for the eight benchmark predictions for the $08 \mathrm{Pu}$ case.

Figure 4. Uncertainty distribution for the eight benchmark predictions for the $19 \mathrm{Pu}$ case

Figure 5. 200 MCUQ benchmark predictions of fuel axial elongation for U-19Pu-10Zr fuel

Figure 6. 200 MCUQ benchmark predictions of FGR for U-19Pu-10Zr fuel....

\section{TABLES}

Table 1. The 49 independent inputs used in the sensitivity analysis.

Table 2. Relative sensitivities of benchmark predictions to 49 independent inputs.................................. 8

Table 3. Example sensitivity fraction calculations for the nine SA predictions to Na pressure for

$\mathrm{U}-8 \mathrm{Pu}-10 \mathrm{Zr}$..

Table 4. PDF estimates for all MCUQ inputs.

Table 5. Average $95 \%$ BISON confidence intervals for each of the eight predictions.

Table 6. Coefficients of determination for all linear correlations between inputs and benchmark predictions.

Table 7. Summary of benchmark inputs with coefficients of determination greater than 0.05 . 


\section{ACRONYMNS}

$\begin{array}{ll}\text { CTE } & \text { coefficient of thermal expansion } \\ \text { EBR-II } & \text { Experimental Breeder Reactor II } \\ \text { EPF } & \text { energy per fission } \\ \text { FFTF } & \text { Fast Flux Test Facility } \\ \text { FGR } & \text { fission gas release } \\ \text { GPA } & \text { Generic Pin Assumption } \\ \text { IFR } & \text { Integral Fast Reactor } \\ \text { LHGR } & \text { linear heat generation rate } \\ \text { MCUQ } & \text { Monte Carlo uncertainty quantification } \\ \text { MOOSE } & \text { Multiphysics Object Oriented Simulation Environment } \\ \text { NSMH } & \text { Nuclear Systems Materials Handbook } \\ \text { ORNL } & \text { Oak Ridge National Laboratory } \\ \text { PDF } & \text { probability density function } \\ \text { PIE } & \text { postirradiation examination } \\ \text { SA } & \text { sensitivity analysis } \\ \text { SE-2 } & \text { SUPERENERGY-2 } \\ \text { UQ } & \text { uncertainty quantification } \\ \text { VTR } & \text { Versatile Test Reactor }\end{array}$




\section{ACKNOWLEDGMENTS}

This work is the result of ongoing efforts supporting the Versatile Test Reactor project and was sponsored by the US Department of Energy Office of Nuclear Energy. Special thanks Dr. Stephen Novascone and Dr. Adam Zabriskie of Idaho National Laboratory for their help on developing BISON simulations. The authors also wish to thank Dr. Jacob Hirschhorn of Oak Ridge National Laboratory for his valuable help in model selection, benchmark standardization, templating, and technical feedback. This work would not have been possible without the efforts of Drs. Doug Crawford and Doug Porter of INL, who both contributed to the original IFR-1 experiment and have been a valuable source of technical knowledge during this research. 


\begin{abstract}
The fuel performance code BISON is being used to evaluate metallic fuel for a new fast-spectrum test reactor called the Versatile Test Reactor, which is being considered by the US Department of Energy. To quantify the accuracy of BISON predictions, researchers at Oak Ridge National Laboratory have been developing a series of benchmarks based on legacy metallic fuel experiments. As part of this effort, the sensitivity of BISON predictions to variations in model inputs and the uncertainties associated with BISON predictions must be established. This report summarizes efforts to perform a comprehensive sensitivity analysis (SA) and uncertainty quantification (UQ) on a benchmark based on the IFR-1 experiment.
\end{abstract}

For the SA, at least one input was chosen from every BISON model and physics module used in the benchmark. The inputs were varied individually in a series of BISON simulations. The resulting variations in benchmark predictions were normalized to calculate sensitivities. The strongest sensitivities were identified and used to inform input selections for the UQ.

The UQ was performed using the Monte Carlo UQ method. A literature review was conducted to estimate uncertainty distributions for the selected inputs, and values were sampled randomly from each distribution in a series of BISON simulations. Variations in the benchmark predictions were used to estimate uncertainty distributions and confidence intervals. It was found that nearly $100 \%$ of benchmark predictions matched the corresponding legacy values within the confidence intervals. However, this is at least partially because of the wide confidence intervals associated with the benchmark predictions. The uncertainty contributions of assumptions in the benchmark, experimental uncertainties, and BISON models were quantified. Some analysis was performed to identify inputs that contributed to the uncertainties. Finally, recommendations are made for future benchmark development and future BISON development.

\title{
1. INTRODUCTION
}

The US Department of Energy is in the process of designing a new fast-spectrum test reactor called the Versatile Test Reactor (VTR). The mission of VTR is to promote the development and deployment of fast-spectrum nuclear energy technologies by providing a modern, fast-spectrum facility for testing advanced nuclear materials, sensors, instruments, and fuels. The fuel performance code BISON is being used to study the thermomechanical fuel performance of the proposed U-Pu-Zr VTR driver fuel [1,2]. However, BISON is still under development and has not been validated within the design space defined by the proposed VTR driver fuel [3].

To inform development and begin quantifying accuracy, Oak Ridge National Laboratory (ORNL) is developing a series of benchmarks based on legacy metallic fuel experiments [4-9]. These benchmarks use BISON to recreate experiments so that BISON predictions can be compared to legacy calculations and postirradiation examination (PIE) data. However, such comparisons do not fully quantify BISON's accuracy. The sensitivities and uncertainties associated with benchmark predictions are also needed. This report documents the first attempt to perform a comprehensive sensitivity analysis (SA) and uncertainty quantification (UQ) of BISON metallic fuel performance predictions. The work utilized a BISON benchmark [4-6] based on the IFR-1 experiment [10-15].

BISON is a finite element-based fuel performance code maintained by Idaho National Laboratory and is under development at a variety of laboratories and institutions [3,16]. BISON is a modern fuel performance code capable of simulating 1D, 1.5D, 2D RZ, 2D R $\theta$, and 3D systems in both steady-state and transient scenarios. It is based on the Multiphysics Object Oriented Simulation Environment 
(MOOSE) [17]. MOOSE solves a series of coupled partial differential equations that govern temperature and dimensional changes. BISON models fuel and cladding irradiation effects such as irradiation-induced fuel swelling and fission gas release (FGR). These effects are input into the MOOSE governing equations to predict fuel and cladding behaviors.

The IFR-1 experiment was one of seven full-size fuel subassemblies irradiated as part of the Integral Fast Reactor (IFR) program. The IFR program was meant to commercialize the pool-type sodium-cooled fast reactor technology developed for Experimental Breeder Reactor II (EBR-II). The program was canceled before the design was finished, but EBR-II and the IFR experiments serve as a basis for both modern reactors like VTR and the fast reactor metallic fuel and cladding models used in BISON $[3,18]$.

Since the IFR concept was based heavily on EBR-II, most of its irradiation experiments were performed in EBR-II. However, the IFR called for longer fuel pins than EBR-II, so full-size fuel pins had to be irradiated in Fast Flux Test Facility (FFTF). IFR-1 contained 169 pins with compositions of U-10Zr ${ }^{1}$, U$8 \mathrm{Pu}-10 \mathrm{Zr}$, and U-19Pu-10Zr. All pins were clad in cold-worked D9 stainless steel. All pins also contained axial blankets of depleted U-10Zr. IFR-1 was irradiated in FFTF between 1986 and 1988 to a target peak burnup of 10 at. \%. The purpose was to ensure that IFR-length fuel pins behaved similarly to EBR-IIlength pins and there were no unexpected dimensional effects.

ORNL researchers have reported results from a generic (not based on any single pin) IFR-1 U-19Pu-10Zr pin benchmark that included a preliminary SA [6]. This assumption meant that (1) all the dimensions were set to the nominal dimensions, (2) all pins were assumed to be interior pins, and (3) coolant flow rates and linear heat generation rates (LHGRs) were equal to the subassembly average values. ORNL has continued refining the modeling approach and developed generic $\mathrm{U}-10 \mathrm{Zr}$ and $\mathrm{U}-8 \mathrm{Pu}-10 \mathrm{Zr}$ pins to include in the benchmark [9,19]. Because of these changes in ORNL's strategies as well as additional development of BISON, predictions in this work do not necessarily match previously reported benchmark predictions.

The IFR-1 benchmark compares benchmark predictions to eight PIE measurements and calculations that were made at the time of the experiment. The PIE measurements include cladding radial dilation, fuel axial growth, and plenum pressure. The calculations include peak burnup, average burnup, peak cladding temperature, coolant outlet temperature, and FGR fraction. All eight measurements and calculations are lumped together as "legacy values" in this report. Many of the legacy values were determined for multiple pins of the same fuel composition. In these cases, benchmark predictions for generic pins were compared against multiple legacy values.

Section 2 of this work presents the setup, results, and analysis of a comprehensive SA done on the IFR-1 benchmark. Section 3 presents the input selection, setup, results, and analysis of the comprehensive UQ. Conclusions are drawn and future work is suggested in Section 4.

\section{SENSITIVITY ANALYSIS}

A SA is an important tool to understand cause and effect in model predictions. The sensitivity of a model output to a model input is the ratio of the relative change in a model output to the relative variation in a model input. For a simple model such as $y=f(x)$, the sensitivity can be expressed using the derivative

$$
S(y \mid x)=\frac{x}{y} \frac{\partial y}{\partial x}
$$

\footnotetext{
${ }^{1}$ All fuel compositions are given in weight percent unless otherwise stated.
} 
where $S(y \mid x)$ is the sensitivity of $y$ to $x$. However, for large, complex computational models, manually calculating derivatives may not be practical. In such cases, a sensitivity study is more appropriate. In a sensitivity study, model inputs are changed one at a time, and then corresponding variations in the model outputs are measured [20]. The sensitivity of a given model output to a given input is estimated according to

$$
S(y \mid x) \cong \frac{x}{y} \frac{\Delta y}{\Delta x}
$$

ORNL researchers previously performed a preliminary SA on the IFR-1 benchmark using orthogonal array sampling [6]. That method accounts for interactions between multiple inputs but requires one simulation for every possible combination of inputs ( $3^{n}$ simulations for $n$ inputs). Therefore, a standard SA was used for this work because it is much less computationally expensive $(2 n+1$ simulations) and because this work analyzed more inputs than the preliminary SA.

\subsection{INPUT SELECTION}

An attempt was made to examine the sensitivities of the eight benchmark predictions to every fuel and blanket dimension, reactor operating condition, and physics model used in the benchmark. However, many physics models had multiple values that could be adjusted. To limit the number of individual inputs, scalar multipliers that are included in models for debugging and sensitivity studies were prioritized, when available. These are labeled multipliers in this report.

Forty-nine independent inputs were selected. These were independent from the perspective of BISON, even though many would be linked physically. For example, LHGR should vary with the fuel radius, but for this work they were treated independently. Ten inputs were also identified that were dependent from the perspective of BISON. The dependent inputs include some dimensional inputs such as gap width (depends on fuel width) or the coefficients used in the LHGR's axial peaking function (depend on fuel height, blanket height, and the LHGR axial peaking factor peak position). The independent inputs are shown in Table 1 along with the nominal values and the BISON objects that primarily utilized the inputs. In cases where the nominal values depend on composition, the compositions are labeled as $00 \mathrm{Pu}, 08 \mathrm{Pu}$, and $19 \mathrm{Pu}$, for $\mathrm{U}-10 \mathrm{Zr}, \mathrm{U}-8 \mathrm{Pu}-10 \mathrm{Zr}$, and $\mathrm{U}-19 \mathrm{Pu}-10 \mathrm{Zr}$, respectively and the nominal value for each composition is given. In cases where multiple BISON objects used the same input value, the object is listed as Multiple. Related inputs are grouped together, and the remainder of this section discusses the groups in more detail. 
Table 1. The 49 independent inputs used in the sensitivity analysis. For each input, the nominal value and primary BISON object that utilized it are also shown. In cases where the nominal value varied with composition, each composition is listed by $\mathrm{Pu}$ wt. \% along with the associated value for each composition. In cases where multiple BISON objects used the same input, the object is labeled Multiple. See the BISON manual for more information on BISON objects and inputs [3].

\begin{tabular}{|c|c|c|c|}
\hline Group & Variable & $\begin{array}{l}\text { Nominal Value } \\
\text { (units) }\end{array}$ & BISON Object \\
\hline \multirow{5}{*}{ 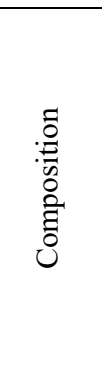 } & ${ }^{235} \mathrm{U}$ enrichment fraction & $\begin{array}{l}\text { 00Pu: } 0.254 \\
\text { 08Pu: } 0.182 \\
\text { 19Pu: } 0.055\end{array}$ & UPuZrFastNeutronFlux \\
\hline & ${ }^{240} \mathrm{Pu}$ enrichment fraction & 0.061 & UPuZrFastNeutronFlux \\
\hline & Blanket initial $\mathrm{Zr}$ atom fraction & 0.224 & UPuZrFissionRate \\
\hline & Fuel initial $\mathrm{Pu}$ atom fraction & $\begin{array}{l}\text { 00Pu: } 0 \\
\text { 08Pu: } 0.069 \\
\text { 19Pu: } 0.163\end{array}$ & Multiple \\
\hline & Fuel initial $\mathrm{Zr}$ atom fraction & $\begin{array}{l}\text { 00/08Pu: } 0.224 \text {, } \\
\text { 19Pu: } 0.225\end{array}$ & Multiple \\
\hline \multirow{4}{*}{$\frac{\vec{\Xi}}{\stackrel{\Xi}{\circ}}$} & Na mass flux multiplier & 1 & CoolantChannel \\
\hline & Na pressure & $1018327(\mathrm{~Pa})$ & Pressure \\
\hline & $\mathrm{Na}$ inlet temperature & $633.15(\mathrm{~K})$ & CoolantChannel \\
\hline & Pin pitch & $0.00823(\mathrm{~m})$ & CoolantChannel \\
\hline \multirow{4}{*}{ 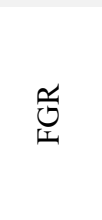 } & Blanket immediate FGR at critical porosity & 0.32 & UPuZrFissionGasRelease \\
\hline & Blanket postcritical FGR fraction & 0.886 & UPuZrFissionGasRelease \\
\hline & $\begin{array}{l}\text { Fuel immediate FGR fraction at critical } \\
\text { porosity }\end{array}$ & $\begin{array}{l}\text { 00Pu: } 0.32 \\
\text { 08/19Pu: } 0.262\end{array}$ & UPuZrFissionGasRelease \\
\hline & Fuel postcritical FGR fraction & $\begin{array}{l}\text { 00Pu: } 0.886 \\
\text { 08/19Pu: } 0.82\end{array}$ & UPuZrFissionGasRelease \\
\hline \multirow{6}{*}{ 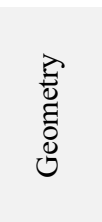 } & Blanket density & $15,800\left(\mathrm{~kg} \mathrm{~m}^{-3}\right)$ & Density \\
\hline & Blanket height & 0.165 & Mesh \\
\hline & Cladding density & $7761 \mathrm{~kg}\left(\mathrm{~m}^{-3}\right)$ & Density \\
\hline & Fuel and blanket radius & $0.00249(\mathrm{~m})$ & Mesh \\
\hline & Fuel density & $15,800\left(\mathrm{~kg} \mathrm{~m}^{-3}\right)$ & Density \\
\hline & Fuel height & $0.9144(\mathrm{~m})$ & Mesh \\
\hline \multirow{4}{*}{ 总 } & Axial peaking factor peak position & $0.59268(\mathrm{~m})$ & UPuZrFissionRate \\
\hline & Blanket LHGR multiplier & 1 & UPuZrFissionRate \\
\hline & Energy per fission & $3.2 \times 10^{-11}(\mathrm{~J})$ & Multiple \\
\hline & LHGR multiplier & 1 & UPuZrFissionRate \\
\hline \multirow{5}{*}{ 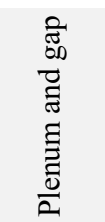 } & Blanket $\mathrm{Na}$ infiltration fraction & 0.13 & UPuZrSodiumLogging \\
\hline & Cladding corrosion multiplier & 1 & MetallicFuelWastage \\
\hline & Fuel Na infiltration fraction & $\begin{array}{l}\text { 00Pu: } 0.13 \\
\text { 08/19Pu: } 0.08\end{array}$ & UPuZrSodiumLogging \\
\hline & Gap thermal conductivity multiplier & 1 & ThermalContact \\
\hline & Plenum initial pressure & $101325(\mathrm{~Pa})$ & PlenumPressure \\
\hline
\end{tabular}


Table 1 continued.

\begin{tabular}{|c|c|c|c|}
\hline Group & Variable & $\begin{array}{l}\begin{array}{l}\text { Nominal Value } \\
\text { (units) }\end{array} \\
\end{array}$ & BISON Object \\
\hline \multirow{13}{*}{$\stackrel{\infty}{.0}$} & Blanket bubble number density & $8.91 \times 10^{17}\left(\mathrm{~m}^{-3}\right)$ & UPuZrGaseousEigenstrain \\
\hline & Blanket equilibrium porosity after FGR & 0.16 & BurnupDependentEigenstrain \\
\hline & Blanket FGR initiating porosity & 0.28 & UPuZrGaseousEigenstrain \\
\hline & Blanket FGR terminating porosity & 0.3 & UPuZrGaseousEigenstrain \\
\hline & Blanket swelling anisotropy & 0.5 & UPuZrGaseousEigenstrain \\
\hline & Cladding swelling multiplier & 1 & D9VolumetricSwellingEigenstrain \\
\hline & Fuel and blanket solid swelling coefficient & 1.5 & BurnupDependentEigenstrain \\
\hline & Fuel and blanket gaseous swelling multiplier & 1 & UPuZrGaseousEigenstrain \\
\hline & Fuel bubble number density & $\begin{array}{l}\text { 00Pu: } 8.91 \times 10^{17} \\
\text { 08/19Pu: } 2.75 \times 10^{17} \\
\left(\mathrm{~m}^{-3}\right)\end{array}$ & UPuZrGaseousEigenstrain \\
\hline & Fuel equilibrium porosity after FGR & $\begin{array}{l}\text { 00Pu: } 0.16 \\
\text { 08/19Pu: } 0.12\end{array}$ & BurnupDependentEigenstrain \\
\hline & Fuel FGR initiating porosity & $\begin{array}{l}\text { 00Pu: } 0.28 \\
\text { 08/19Pu: } 0.25\end{array}$ & UPuZrGaseousEigenstrain \\
\hline & Fuel FGR terminating porosity & $\begin{array}{l}\text { 00Pu: } 0.3 \text {, } \\
\text { 08/19Pu: } 0.27\end{array}$ & UPuZrGaseousEigenstrain \\
\hline & Fuel swelling anisotropy & 0.5 & UPuZrGaseousEigenstrain \\
\hline \multirow{8}{*}{ 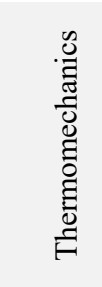 } & Blanket thermal conductivity multiplier & 1 & UPuZrThermal \\
\hline & Cladding creep multiplier & 1 & D9CreepUpdate \\
\hline & Cladding CTE multiplier & 1 & D9ThermelExpansionEigenstrain \\
\hline & Fast neutron flux fraction & 0.9 & UPuZrFastNeutronFlux \\
\hline & Fuel and blanket CTE multiplier & 1 & UPuZrThermalExpansionEigenstrain \\
\hline & Fuel creep multiplier & 1 & UPuZrCreepUpdate \\
\hline & Fuel elasticity multiplier & 1 & UPuZrElasticityTensor \\
\hline & Fuel thermal conductivity multiplier & 1 & UPuZrThermal \\
\hline
\end{tabular}

\subsubsection{Composition}

The composition group in Table 1 lists inputs related to the chemical and isotopic composition of the fuel and blanket slugs. It includes the $\mathrm{U}$ and $\mathrm{Pu}$ atom fractions which are converted from wt. \% of each composition, as well as ${ }^{235} \mathrm{U}$ and ${ }^{240} \mathrm{Pu}$ enrichments (BISON assumed only two Pu isotopes were present in the fuel).

\subsubsection{Coolant}

The coolant group included inputs that affect the coolant model. It contained a multiplier applied to the coolant mass flux, the coolant inlet temperature, the coolant pressure, and the pin pitch. The mass flux $\left(\mathrm{kg} \mathrm{s}^{-1} \mathrm{~m}^{-2}\right)$ was the mass flow rate per unit area; it was the input that controls the coolant flow rate. The $\mathrm{Na}$ inlet temperature $(\mathrm{K})$ and pressure $(\mathrm{Pa})$ were the temperature and pressure at which the reactor coolant entered the core. The temperature increased as the coolant traveled up the core, but BISON assumed a constant pressure throughout the coolant channel.

The pin pitch was the center-to-center distance between two adjacent pins. IFR-1 consisted of a hexagonal subassembly sleeve with 169 pins inside. Each pin was wrapped in a helical spacer wire. The nominal pin pitch was calculated based on the pin and spacer wire diameters $[5,6]$.

\subsubsection{Fission gas release}

The FGR group includes inputs for BISON's U-Pu-Zr FGR model [3]. The semi-empirical model assumed no FGR occurred until a critical porosity was reached through fission gas swelling. Once the critical porosity was reached, a set fraction of fission gas was immediately released, and a different 
fraction of subsequent fission gas was released immediately upon being generated. The critical porosity and both FGR release fractions could be set individually. The total amount of fission gas produced, however, was a linear function of burnup.

\subsubsection{Geometry}

The geometry group included all the inputs needed to define the fuel and blanket dimensions. It also included densities of the fuel, blankets, and cladding. Several dependent inputs, such as gap width and mesh locations of edges of the fuel and blanket slugs, were calculated based on the inputs in this group. To simplify mesh generation, one radius was used to define the fuel and blankets and one blanket height was used to represent both the top and bottom blankets.

Cladding dimensions were not included in the sensitivity analysis. This was done intentionally. During development of the benchmarks and literature review of uncertainties, it became clear that (1) cladding dimensions are accurately recorded in experimental descriptions, (2) cladding dimensions are held to very tight tolerances, so uncertainties were essentially zero, and (3) cladding uncertainties are not generally recorded because they are so small. Because of these findings, it was decided that cladding dimensions were not likely to affect the experiment or benchmark.

\subsubsection{Linear heat generation rate}

The LHGR group contained four inputs that affected the heat generation profile of the fuel. These included a multiplier applied to the average LHGR, the axial position of the peak LHGR, a multiplier applied to the blanket LHGR functions [6], and the average energy released per fission.

The IFR-1 benchmark defined both an average LHGR, which varies with time based on the experimental power history [14], and an axial peaking function, $p(z)$, which is constant with time but varied with axial position. The axial peaking function was a polynomial with an average value of 1 . Previously it was a fourth-order polynomial [6], but for this work it was reduced to a third order polynomial:

$$
p(z)=c_{0}+c_{1} z+c_{2} z^{2}+c_{3} z^{3}
$$

where $z$ was the axial position; $p(z)$ was the peaking function; and $c_{0}, c_{1}, c_{2}$, and $c_{3}$ were the polynomial coefficients. The polynomial is bound by the following conditions:

$$
\begin{gathered}
p\left(z_{b}\right)=p_{b}, \\
p\left(z_{t}\right)=p_{t}, \\
\frac{d p}{d z}\left(z_{p}\right)=0, \\
\frac{1}{z_{t}-z_{b}} \int_{z_{b}}^{z_{t}} p(z) d z=1,
\end{gathered}
$$

where $z_{b}, z_{t}$, and $z_{p}$ were the position of the bottom of the fuel column, the position of the top of the fuel column, and the position of the profile's peak, respectively. The nominal values and the set peak values of $p_{b}$ and $p_{t}$ were chosen to match the axial profile calculated at the time of the experiment $[6,14]$. The bottom, peak, and top positions of the fuel changed depending on the inputs. Note that the positions in Eq. (4), including the axial position of the peak LHGR, were measured from the bottom of the pin according to the mesh dimensions [5,6]. The polynomial coefficients were determined for each simulation depending on the independent inputs in Eq. (4). For the nominal case, they were $c_{0}=0.10295, c_{1}=$ $3.80547, c_{2}=-3.2177$, and $c_{3}=0.00822$. 


\subsubsection{Plenum and Gap}

The plenum and gap group contained four inputs related to the plenum and gap region between the fuel and cladding. The blanket and fuel $\mathrm{Na}$ infiltration fractions represented the fraction of porosity that fills with $\mathrm{Na}$ after FGR occurred. The group also included the initial plenum pressure and a multiplier for the thermal conductivity of $\mathrm{Na}$ in the gap.

\subsubsection{Swelling}

The swelling group contained 13 inputs for the fuel, blanket, and cladding swelling models. The fuel and blanket swelling models contain both solid and gaseous swelling components. The bubble number densities, initiating porosities, terminating porosities, anisotropies, and gaseous swelling multipliers were for the gaseous swelling models. The equilibrium porosity after FGR and solid swelling coefficient were both for the solid swelling models. The swelling models could be very complex, and a thorough description of their behaviors and the meanings of most of these inputs is beyond the scope of this work. For more detailed discussions, see the BISON manual [3].

The equilibrium porosities after FGR are not standard inputs to the model. In response to poor swelling predictions in the IFR-1 benchmark [5,6], ORNL added an extra model to the benchmark to allow solid swelling to partially close vented fission gas bubbles $[8,19]$ in a process called hot pressing. This model was not a standard BISON model. Rather, it was a placeholder until a high-quality hot pressing model became available in BISON. A more thorough explanation of ORNL's hot pressing approximation is available in a separate report [19].

\subsubsection{Thermomechanics}

The thermomechanics group included eight inputs that affected the coefficients of thermal expansion (CTEs), thermal conductivities, and creep rates in the fuel, blankets, and cladding. Many creep models include multiple temperature- and irradiation-dependent creep regimes. However, the same multiplier was applied to all creep regimes to simplify comparisons between different materials. All inputs in this group were multipliers except for the fast neutron flux fraction. The fast neutron flux fraction was the fraction of neutrons in the fast energy spectrum. This input was used in the cladding creep and swelling models.

\subsection{ANALYSIS SETUP}

A standard SA examining $n$ inputs requires $2 n+1$ simulations. The first is a simulation performed using only the nominal input values. Then, two simulations are conducted for each input: one with a reduced input value and one with an increased value. For this work, each input was increased or reduced by $2 \%$ of its nominal value.

In addition to the eight outputs with legacy values, the SA also examined the peak fuel temperature. This benchmark prediction was compared to legacy values in other benchmarks [8]. Including it here will facilitate a more direct comparison between this work and future benchmark SAs.

A template IFR-1 BISON input file was written with inputs values replaced with variables. Variables followed the convention $\%\{$ variable_name $\}$ to make them easy to parse. A Python script was used to fill in the template with input values for each simulation. The input values and simulation results were stored in CSV files. 
The simulations were performed using ORNL's BISON@ORNL repository [19], which can run up to 32 simulations concurrently per node. All predictions varied with simulation time, but only one point in time was needed for sensitivity calculations. The sensitivity time was chosen to be the end of reactor irradiation, prior to reactor cooldown. The sensitivities were calculated according to Eq. (2).

\subsection{RESULTS}

The sensitivities were calculated separately for the three fuel compositions. They generally did not vary significantly between compositions, except for the $\mathrm{Pu}$ inputs of fuel initial $\mathrm{Pu}$ atom fraction and ${ }^{240} \mathrm{Pu}$ enrichment. The average relative sensitivities of the nine benchmark predictions to the 49 inputs are shown in Table 2. The inputs are listed in alphabetical order. Sensitivities with absolute values greater than 0.1 are bold, sensitivities with absolute values greater than 1 are highlighted in dark green, and inputs with no measurable sensitivities are grayed out.

Table 2. Relative sensitivities of benchmark predictions to 49 independent inputs. Measurable sensitivities include three decimal places even when they round to zero. Sensitivities of exactly zero have no decimal places.

Sensitivities with absolute values greater than 0.1 are bold, sensitivities with absolute values greater than 1 are highlighted in dark green, and inputs with no sensitivities of at least \pm 0.001 are grayed out.

\begin{tabular}{|c|c|c|c|c|c|c|c|c|c|}
\hline Input & 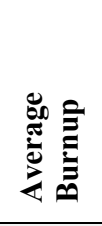 & 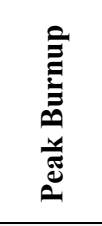 & 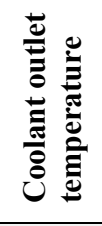 & 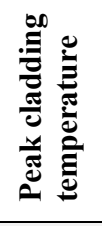 & 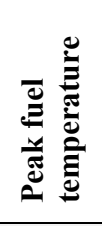 & & 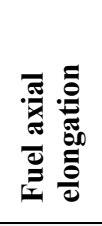 & 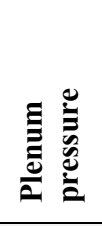 & 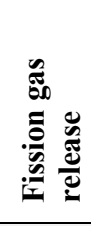 \\
\hline Axial peaking factor peak position & -0.017 & -0.165 & -0.004 & 0.020 & 0.042 & -0.071 & 0.096 & -0.035 & 0.000 \\
\hline Blanket bubble number density & 0.000 & 0.000 & 0.000 & 0.000 & -0.001 & -0.001 & 0.017 & -0.019 & 0.000 \\
\hline Blanket density & 0.000 & 0.000 & 0.000 & 0.000 & 0.001 & -0.004 & -0.070 & 0.003 & 0.000 \\
\hline $\begin{array}{l}\text { Blanket equilibrium porosity after } \\
\text { FGR }\end{array}$ & 0.000 & 0.000 & 0.000 & 0.000 & 0.000 & 0.000 & 0.000 & 0.000 & 0.000 \\
\hline Blanket FGR initiating porosity & 0.000 & 0.000 & 0.000 & 0.000 & 0.000 & 0.000 & 0.000 & 0.000 & 0.000 \\
\hline Blanket FGR terminating porosity & 0.000 & 0.000 & 0.000 & 0.000 & 0.000 & 0.000 & 0.000 & 0.000 & 0.000 \\
\hline Blanket height & -0.011 & 0.043 & 0.002 & 0.002 & -0.007 & 0.138 & -0.124 & 0.382 & -0.021 \\
\hline $\begin{array}{l}\text { Blanket immediate FGR fraction at } \\
\text { critical porosity }\end{array}$ & 0.000 & 0.000 & 0.000 & 0.000 & 0.000 & 0.000 & 0.000 & 0.000 & 0.000 \\
\hline Blanket initial $\mathrm{Zr}$ atom fraction & 0.000 & 0.000 & 0.000 & 0.000 & 0.000 & -0.002 & -0.011 & 0.001 & 0.000 \\
\hline Blanket LHGR multiplier & 0.000 & 0.000 & 0.009 & 0.007 & 0.006 & 0.018 & -0.015 & 0.070 & -0.027 \\
\hline Blanket Na infiltration fraction & 0.000 & 0.000 & 0.000 & 0.000 & 0.000 & 0.000 & 0.000 & 0.000 & 0.000 \\
\hline Blanket postcritical FGR fraction & 0.000 & 0.000 & 0.000 & 0.000 & 0.000 & 0.000 & 0.000 & 0.000 & 0.000 \\
\hline Blanket swelling anisotropy & 0.000 & 0.000 & 0.000 & 0.000 & -0.002 & -0.001 & 0.003 & 0.007 & 0.000 \\
\hline $\begin{array}{l}\text { Blanket thermal conductivity } \\
\text { multiplier }\end{array}$ & 0.000 & 0.000 & 0.000 & 0.000 & 0.000 & 0.000 & 0.000 & 0.000 & 0.000 \\
\hline Cladding corrosion multiplier & 0.000 & 0.000 & 0.000 & 0.000 & 0.000 & 0.000 & 0.000 & 0.000 & 0.000 \\
\hline Cladding density & 0.000 & 0.000 & 0.000 & 0.000 & 0.000 & 0.004 & -0.001 & 0.000 & 0.000 \\
\hline Cladding creep multiplier & 0.000 & 0.000 & 0.000 & 0.000 & 0.000 & 0.078 & -0.028 & -0.011 & 0.000 \\
\hline Cladding CTE multiplier & 0.000 & 0.000 & 0.000 & -0.003 & 0.001 & 0.125 & -0.312 & -0.060 & 0.000 \\
\hline Cladding swelling multiplier & 0.00 & 0.000 & 0.000 & -0.004 & -0.001 & 0.762 & -0.025 & -0.083 & -0.001 \\
\hline Energy per fission & -1.000 & -1.000 & -0.009 & 0.003 & 0.015 & -2.456 & 0.502 & -0.792 & -0.047 \\
\hline
\end{tabular}


Table 2 continued.

\begin{tabular}{|c|c|c|c|c|c|c|c|c|c|}
\hline Input & 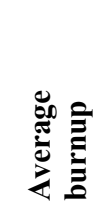 & 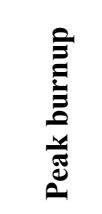 & 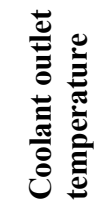 & 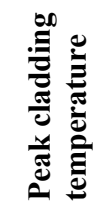 & 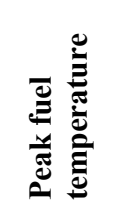 & 些: & 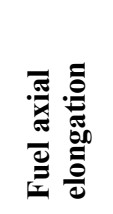 & 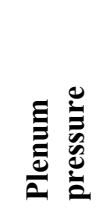 & 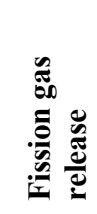 \\
\hline Fast neutron flux fraction & 0.000 & 0.000 & 0.000 & -0.010 & 0.001 & 2.324 & -0.326 & -0.341 & 0.000 \\
\hline Fuel and blanket CTE multiplier & 0.000 & 0.000 & 0.000 & 0.003 & -0.004 & -0.007 & 0.668 & 0.025 & 0.000 \\
\hline $\begin{array}{l}\text { Fuel and blanket gaseous swelling } \\
\text { multiplier }\end{array}$ & 0.000 & 0.000 & 0.000 & 0.000 & -0.001 & 0.012 & -0.157 & 0.081 & 0.048 \\
\hline Fuel and blanket radius & -2.002 & -2.002 & -0.018 & 0.095 & -0.157 & -4.821 & 30.698 & 1.202 & -0.107 \\
\hline $\begin{array}{l}\text { Fuel and blanket solid swelling } \\
\text { coefficient }\end{array}$ & 0.000 & 0.000 & 0.000 & 0.002 & -0.020 & -0.001 & 0.282 & 0.013 & 0.000 \\
\hline Fuel bubble number density & 0.000 & 0.000 & 0.000 & 0.000 & 0.000 & -0.010 & 0.081 & -0.021 & -0.025 \\
\hline Fuel creep multiplier & 0.000 & 0.000 & 0.000 & 0.000 & 0.001 & -0.008 & -0.082 & 0.009 & 0.000 \\
\hline Fuel density & -1.000 & -1.000 & -0.009 & 0.002 & 0.015 & -2.344 & -0.140 & 0.242 & 0.027 \\
\hline Fuel elasticity multiplier & 0.000 & 0.000 & 0.000 & 0.000 & 0.000 & -0.006 & 0.005 & 0.000 & 0.000 \\
\hline Fuel equilibrium porosity after FGR & 0.000 & 0.000 & 0.000 & 0.000 & 0.000 & 0.000 & 0.000 & 0.000 & 0.000 \\
\hline Fuel FGR initiating porosity & 0.000 & 0.000 & 0.000 & 0.000 & 0.000 & 0.012 & 0.007 & -0.021 & -0.018 \\
\hline Fuel FGR terminating porosity & 0.000 & 0.000 & 0.000 & 0.024 & 0.022 & 0.022 & 7.583 & 0.494 & -0.046 \\
\hline Fuel height & 0.011 & 0.114 & 0.172 & 0.146 & 0.071 & 0.667 & -0.523 & 2.345 & 0.078 \\
\hline $\begin{array}{l}\text { Fuel immediate FGR fraction at } \\
\text { critical porosity }\end{array}$ & 0.000 & 0.000 & 0.000 & 0.000 & 0.000 & 0.010 & -0.020 & 0.035 & 0.038 \\
\hline Fuel initial $\mathrm{Pu}$ atom fraction & 0.002 & 0.002 & 0.000 & 0.004 & 0.005 & -0.744 & 0.106 & 0.091 & 0.001 \\
\hline Fuel initial $\mathrm{Zr}$ atom fraction & 0.129 & 0.129 & 0.001 & 0.000 & 0.032 & 0.083 & 0.033 & 0.002 & -0.001 \\
\hline Fuel Na infiltration fraction & 0.000 & 0.000 & 0.000 & 0.000 & -0.004 & -0.004 & -0.004 & 0.000 & 0.000 \\
\hline Fuel postcritical FGR fraction & 0.000 & 0.000 & 0.000 & 0.000 & 0.000 & 0.086 & -0.066 & 0.900 & 0.962 \\
\hline Fuel swelling anisotropy & 0.000 & 0.000 & 0.000 & 0.000 & 0.000 & -0.004 & -0.018 & 0.002 & 0.000 \\
\hline Fuel thermal conductivity multiplier & 0.000 & 0.000 & 0.000 & 0.000 & 0.000 & 0.000 & 0.000 & 0.000 & 0.000 \\
\hline $\begin{array}{l}\text { Gap thermal conductivity } \\
\text { uncertainty multiplier }\end{array}$ & 0.000 & 0.000 & 0.000 & 0.000 & -0.010 & -0.008 & 0.027 & -0.002 & -0.001 \\
\hline LHGR multiplier & 1.000 & 1.000 & 0.205 & 0.206 & 0.260 & 3.013 & -0.743 & 0.958 & 0.066 \\
\hline Na mass flux multiplier & 0.000 & 0.000 & -0.196 & -0.175 & -0.109 & -0.466 & 0.198 & -0.149 & -0.009 \\
\hline Na pressure & 0.000 & 0.000 & 0.000 & 0.000 & 0.000 & -0.029 & 0.016 & 0.004 & 0.000 \\
\hline $\mathrm{Na}$ inlet temperature & 0.000 & 0.000 & 0.826 & 0.779 & 0.622 & 3.046 & -1.274 & 0.389 & 0.048 \\
\hline Pin pitch & 0.000 & 0.000 & -1.068 & -0.949 & -0.582 & -2.312 & 0.974 & -0.786 & -0.045 \\
\hline Plenum initial pressure & 0.000 & 0.000 & 0.000 & 0.000 & -0.001 & 0.004 & -0.010 & 0.052 & 0.000 \\
\hline${ }^{240} \mathrm{Pu}$ enrichment & 0.000 & 0.000 & 0.000 & 0.000 & 0.001 & 0.032 & -0.006 & -0.003 & 0.000 \\
\hline${ }^{235} \mathrm{U}$ enrichment & 0.000 & 0.000 & 0.000 & 0.005 & 0.001 & -1.014 & 0.136 & 0.165 & 0.000 \\
\hline
\end{tabular}

\subsection{DISCUSSION}

The strongest sensitivity was that of fuel axial elongation to fuel and blanket radius: 30.7 . The second strongest sensitivity was the sensitivity of fuel axial elongation to fuel FGR terminating porosity (7.6). There was a total of 22 sensitivities with absolute values of 1 or more. Of the 22, eight were of the cladding radial dilation, each burnup prediction had four, fuel axial elongation had three, plenum pressure had two, and coolant outlet temperature had one. The coolant outlet temperature, peak cladding temperature, and FGR had no high sensitivities.

Overall, the benchmark was most sensitive to the fuel and blanket radius. Five predictions were highly sensitive to it, and the single strongest sensitivity was that of fuel axial elongation to fuel and blanket radius. Energy per fission, fuel density, and the LHGR multiplier were each associated with three high sensitivities. Na inlet temperature and pin pitch were both associated with two high sensitivities. Four inputs were associated with one high sensitivity each: fast neutron flux fraction, fuel FGR terminating porosity, fuel height, and ${ }^{235} \mathrm{U}$ enrichment. 
Some of the calculated sensitivities are unexpected. The sensitivity of the fuel axial elongation to the fuel and blanket gaseous swelling multiplier is negative, so that increasing the gaseous swelling decreases the overall swelling. However, this can be explained by the FGR behavior of the fuel. Both gaseous and solid swelling contribute to overall fuel swelling until the gaseous pores grow enough to interconnect and vent their gas (usually around a burnup of $2 \%$ ). At that point, gaseous swelling ceases completely, and solid swelling causes the vented pores to close. If gaseous swelling is slowed, then more solid swelling will occur prior to pore venting.

The negative sensitivity of cladding radial dilation to fuel and radius is also unexpected. However, it has already been established in BISON benchmark studies that the fuel is too malleable to mechanically strain the cladding under these experimental conditions $[6,8]$. This explains why the sensitivity is not positive. However, the fact that it is strongly negative suggests a secondary effect, possibly an effect on cladding creep or cladding swelling. This would not be surprising given that the simulation is very sensitive to fuel and blanket radius overall.

These results have important implications for BISON models as well as future experiments. Modelers developing BISON simulations should take great care to make the fuel and blanket radius, LHGR, Na inlet temperature, and pin pitch as accurate as possible. Future experiments should likewise use tight tolerances for these values and/or measure them as accurately as possible. Doing so will significantly reduce the uncertainty of BISON predictions.

\section{UNCERTAINTY QUANTIFICATION}

Uncertainty quantification is an analysis that measures the uncertainty distributions of model predictions, given uncertainty distributions of model inputs. This study utilized Monte Carlo UQ (MCUQ) - a method by which model inputs are randomly sampled from uncertainty distributions and responding variations in the model predictions are used to construct an output uncertainty distribution. One of the advantages of MCUQ is that only the inputs and predictions are needed to quantify the uncertainties. The model can otherwise be treated as a black box. MCUQ was also used to quantify the uncertainties of the preliminary VTR driver fuel simulation [21].

One challenge associated with MCUQ is estimating the uncertainty distributions of the model inputs. For BISON metallic fuel materials, the documentation often does not include uncertainty estimates[3,18], and the original data are often not publicly available because of ownership or export control requirements. Multiple methods were used in this work to estimate uncertainties from public sources. However, some details of one uncertainty distribution had to be omitted because of export control concerns.

\subsection{INPUT SELECTION}

The first criterion for selecting the MCUQ inputs was based on the results of the SA in the previous section. The maximum absolute sensitivity of each benchmark prediction was tabulated for each

composition. Then sensitivity fractions were calculated by dividing individual sensitivities by the absolute maximum sensitivity of each prediction. Only inputs associated with at least one sensitivity fraction of at least $\pm 1 \%$ for any composition could be selected for the MCUQ. An example of this calculation for $\mathrm{Na}$ pressure with $\mathrm{U}-8 \mathrm{Pu}-10 \mathrm{Zr}$ fuel is shown in Table 3 . This reduced the number of candidate inputs from the 49 sensitivity inputs to 29 : 
- axial peaking factor peak position,

- blanket height,

- blanket LHGR multiplier,

- cladding creep multiplier,

- cladding CTE multiplier,

- cladding swelling multiplier,

- energy per fission (EPF),

- fast neutron flux fraction,

- fuel and blanket CTE multiplier,

- fuel and blanket gaseous swelling multiplier,

- fuel and blanket radius,

- fuel and blanket solid swelling coefficient,

- fuel bubble number density,

- fuel density,

- fuel FGR initiating porosity,
- fuel FGR terminating porosity,

- fuel height,

- fuel immediate FGR fraction at critical porosity,

- fuel initial Pu atom fraction,

- fuel initial $\mathrm{Zr}$ atom fraction,

- fuel postcritical FGR fraction,

- gap thermal conductivity multiplier,

- LHGR multiplier,

- Na mass flux multiplier,

- Na inlet temperature,

- pin pitch,

- plenum initial pressure,

- ${ }^{240} \mathrm{Pu}$ enrichment, and

- ${ }^{235} \mathrm{U}$ enrichment.

Table 3. Example sensitivity fraction calculations for the nine SA predictions to Na pressure for U-8Pu-10Zr. Each sensitivity was divided by the peak sensitivity of that prediction. The maximum sensitivity fraction was $0.6 \%$, with similar results for the other compositions. Therefore, Na pressure did not meet this criterion.

\begin{tabular}{lccc}
\hline & & & \\
Prediction & & & \\
& & & \\
Average burnup & 0.000 & -2.002 & $-0.0 \%$ \\
Peak burnup & 0.000 & -2.002 & $-0.0 \%$ \\
Coolant outlet temperature & 0.000 & -1.068 & $-0.0 \%$ \\
Peak cladding temperature & 0.000 & -0.949 & $-0.0 \%$ \\
Peak fuel temperature & 0.000 & 0.617 & $0.0 \%$ \\
Cladding radial dilation & -0.029 & -4.793 & $0.6 \%$ \\
Fuel axial elongation & 0.038 & 34.711 & $0.1 \%$ \\
Fission gas release & -0.001 & 0.971 & $-0.1 \%$ \\
Plenum pressure & 0.003 & 2.297 & $0.1 \%$ \\
\hline
\end{tabular}

Other adjustments were made to finalize selection of the MCUQ inputs. The blanket height input was separated into two inputs: the bottom blanket height and the top blanket height. In addition, the FGR and fuel swelling models utilized multiple inputs, but experimental uncertainties could not distinguish between values. Therefore, only the inputs with the highest average sensitivity fractions were used to represent these models. This resulted in the fuel bubble number density, fuel immediate FGR fraction, fuel FGR initiating porosity, and fuel FGR terminating porosity not being used. Finally, the uncertainty in the fuel initial $\mathrm{Pu}$ fraction was so low that it did not affect the input within the number of significant digits used in the input file template, so it was also not used. This brought the number of inputs for the MCUQ to 25 .

Also note that out of 13 blanket-specific inputs, only two - the blanket height and LHGR multiplier - had significant sensitivities. This suggests that the blankets were not significantly affecting fuel performance. This is hardly a surprising conclusion given the low LHGR and burnup in the blankets. Therefore, the MCUQ did not include blankets in the following inputs: fuel gaseous swelling multiplier, fuel CTE multiplier, and fuel solid swelling coefficient. The only four MCUQ inputs that affected blankets were the 
blanket bottom height, the blanket top height, the blanket LHGR multiplier, and the fuel and blanket radius.

\subsection{BENCHMARK UNCERTAINTY ESTIMATES}

Each input in the MCUQ required a probability density function (PDF) [22]. For the purposes of this work, it was assumed that each input uncertainty could be defined in terms of a one of three PDFs; each of which could depended on a mean, $\mu$, and standard deviation, $\sigma$. The first PDF was a uniform distribution:

$$
p_{u}(x, \mu, \sigma)=\left\{\begin{array}{rr}
\frac{1}{4 \sigma}, & \mu-2 \sigma \leq x \leq \mu+2 \sigma \\
0, & \text { otherwise }
\end{array},\right.
$$

where $x$ is an input value and $p_{u}$ is the probability of that value being sampled from the distribution. The second PDF is a normal distribution:

$$
p_{n}(x, \mu, \sigma)=\frac{1}{\sigma \sqrt{2 \pi}} \exp \left(-\frac{1}{2}\left(\frac{x-\mu}{\sigma}\right)^{2}\right)
$$

where $p_{n}$ is the probability of sampling $x$. The third PDF is a log-normal distribution:

$$
p_{\ell}(x, \mu, \sigma)=\mu \cdot 10^{p_{n}(x, 0, \sigma)},
$$

where $p_{\ell}$ is the probability of sampling $x$.

The inputs were divided into three groups depending on the source of the uncertainty. The first group, Generic Pin Assumption (GPA), included inputs for which values were known for specific pins but were not used because of the decision to make the benchmark from generic pins. The second group, Experiment, included inputs that depended on the experimental conditions. Experiment uncertainties could come from tolerance in the experiment specifications, measurement uncertainties, or unrecorded conditions - all of which contributed to uncertainty in the benchmark predictions.

The third group of inputs was the BISON Models group. This group included inputs for the models and correlations that BISON used to predict fuel behavior. The PDF approximations in this group could come from margins of error calculated in a model's documentation, noise in experimental data reported in a model's documentation, noise in experimental data in the literature, or comparisons with predictions of other models. Two inputs did not necessarily fit neatly into one group: the fast neutron flux fraction and the EPF. The fast neutron flux fraction depended on the fuel composition, reactor operating conditions, and neighboring subassemblies. It could have been included in either the GPA or Experiment groups, but it was decided that it fit better in the Experiment group because the actual value for each pin was not included in the IFR-1 documentation [10-14]. The EPF also depends on fuel composition and reactor operating conditions. However, BISON uses it as an important input in multiple models, making it extremely important for the BISON Models group, so that is where it was placed.

Ideally, one could determine each group's confidence intervals separately. However, the predicted uncertainty distributions caused by multiple inputs can interact in unexpected ways. Therefore, a strategy was developed to examine each group separately while also accounting for input interactions between groups. Three MCUQ studies were conducted for each composition. The first study sampled inputs from the GPA group with 120 simulations per composition (360 in total). The second study sampled inputs from both the GPA and Experiment groups. It also used 120 simulations per composition. The third study 
included sampled from all three groups and used 200 simulations per composition (600 in total). This strategy allowed the contributions of each group to be observed while maintaining potential interactions between groups.

The PDFs were estimated based on available literature information. They are summarized in Table 4, including the form of the PDF, the mean, and the standard deviation. References are also provided, but they do not necessarily include enough context to determine how the distribution was approximated. Engineering judgement was used when the available literature was contradictory or lacked sufficient information to clearly define the PDF. Additional discussion of the inputs within each group is provided in the remainder of this section.

Table 4. PDF estimates for all MCUQ inputs. The inputs were divided into three groups depending on the sources of their uncertainties. In cases where the nominal value varied with composition, the values for each composition are given. References are included. See the discussion below for more information on how the PDFs were approximated.

\begin{tabular}{|c|c|c|c|c|c|}
\hline Group & Input & PDF & Mean (units) & $\begin{array}{l}\text { Standard } \\
\text { deviation }\end{array}$ & References \\
\hline \multirow{8}{*}{ 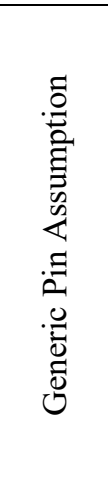 } & Blanket bottom height & Normal & $0.165(\mathrm{~m})$ & 0.00213 & [12] \\
\hline & Blanket top height & Normal & $0.165(\mathrm{~m})$ & 0.00213 & [12] \\
\hline & Fuel and blanket radius & Normal & $0.00249(\mathrm{~m})$ & $1.667 \times 10^{-5}$ & {$[12]$} \\
\hline & Fuel density & Uniform & $\begin{array}{l}15,800 \\
\left(\mathrm{~kg} \mathrm{~m}^{-3}\right)\end{array}$ & 125 & [23] \\
\hline & Fuel height & Normal & $0.9144(\mathrm{~m})$ & 0.0021 & [12] \\
\hline & Fuel initial $\mathrm{Zr}$ atom fraction & Normal & 0.225 & 0.00667 & {$[12]$} \\
\hline & ${ }^{240} \mathrm{Pu}$ enrichment & Normal & 0.061 & $\begin{array}{l}\text { 00/08Pu: } 0 \text {, } \\
\text { 19Pu: } 0.0006\end{array}$ & {$[12]$} \\
\hline & ${ }^{235} \mathrm{U}$ enrichment & Normal & $\begin{array}{l}\text { 00Pu: } 0.252 \text {, } \\
\text { 08Pu: } 0.175 \text {, } \\
\text { 19Pu: } 0.045\end{array}$ & 0.0033 & [12] \\
\hline \multirow{8}{*}{ 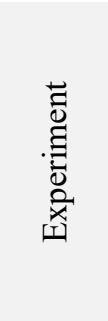 } & Axial peaking factor peak position & Uniform & $0.5851(\mathrm{~m})$ & 0.0383 & [14] \\
\hline & Blanket LHGR multiplier & Normal & 1 & 0.15 & \\
\hline & Fast neutron flux fraction & Normal & 0.9 & 0.03 & [24] \\
\hline & LHGR multiplier & Normal & 1 & 0.026 & {$[10]$} \\
\hline & Na mass flux multiplier & Normal & 1 & 0.04 & [10] \\
\hline & $\mathrm{Na}$ inlet temperature & Normal & $633.15(\mathrm{~K})$ & 30.2 & [10] \\
\hline & Pin pitch & Uniform & $0.00912(\mathrm{~m})$ & $4.45 \times 10^{-4}$ & {$[14,25]$} \\
\hline & Plenum initial pressure & Normal & $101,325(\mathrm{~Pa})$ & 2,976 & [26] \\
\hline \multirow{9}{*}{$\begin{array}{l}\frac{n}{0} \\
\frac{0}{0} \\
\sum_{0} \\
0 \\
\frac{n}{n}\end{array}$} & Cladding creep multiplier & Normal & 1 & 0.025 & [27] \\
\hline & Cladding CTE multiplier & Normal & 1 & 0.0017 & [28] \\
\hline & Cladding swelling multiplier & Normal & 1 & 0.0056 & [29] \\
\hline & EPF & Uniform & $3.2 \times 10^{-11}(\mathrm{~J})$ & $0.1 \times 10^{-11}$ & [30] \\
\hline & Fuel CTE multiplier & Normal & 1 & 0.06 & [23] \\
\hline & Fuel gaseous swelling multiplier & Log-normal & 1 & 0.5 & \\
\hline & Fuel solid swelling coefficient & Normal & $\begin{array}{l}1.5 \text { (\% strain/ } \\
\% \text { burnup) }\end{array}$ & 0.5 & [31] \\
\hline & Fuel postcritical FGR fraction & Normal & $\begin{array}{l}\text { 00Pu: } 0.886 \\
\text { 08/19Pu: } 0.82\end{array}$ & 0.03 & [32] \\
\hline & Gap thermal conductivity prefactor & Normal & 0 & 0.5 & [33] \\
\hline
\end{tabular}

\subsubsection{Generic Pin Assumption}

The GPA group included inputs related to as-manufactured pin dimensions and properties. These properties were generally known for individual pins but were ignored in the benchmark in favor of 
nominal values. All except one came from the IFR-1 pin manufacturing report [12], which included manufacturing tolerances on pages 3-4. The manufacturing tolerances were assumed to be equal to three standard deviations in a normal distribution PDF.

The IFR-1 pin manufacturing report did not include a manufacturing tolerance for the density [12], so the variation was estimated based on density measurements gathered by Middlemas and Janney [23].

\subsubsection{Experiment}

The Experiment group contained inputs related to the reactor conditions during the experiment. These could be conditions that were recorded but had operating or measurement tolerances. They could also be conditions that were not recorded in experiment reports.

The 2011 IFR-1 report included an estimate of the axial LHGR profile for a single U-19Pu-10Zr pin [14]. It also had isotopic gamma scans that were used to estimate the axial peaking profile of the fuel and blankets $[5,6]$. The PDF of the location of the peak LHGR and blanket LHGRs was estimated based on noise in the isotopic composition.

The fast neutron flux fraction's nominal value was BISON's default value. The BISON manual references Withop et al. for that value $[3,24]$. It appears that the default value was determined by taking the average ratio of neutron cross sections at $0 \mathrm{MeV}$ to the cross sections at $0.1 \mathrm{MeV}$ in Withop et al.'s Tables 4-2 and 4-3 [24]. The standard deviation was calculated based on the measurements in those tables.

There is no record of the pre-irradiation plenum pressure in the IFR-1 documentation. Therefore, it was assumed that the pressure was equal to 1 atmosphere $(101,325 \mathrm{~Pa})[5,6]$. The variation in pressure was estimated based on Arco, ID weather data available online [26].

The standard deviations of the average LHGR, coolant mass flux, and coolant inlet temperature were taken from $3 \sigma$ safety estimates in the IFR-1 safety analysis [10]. The pin pitch was not recorded in the IFR-1 documentation but could be calculated in one of two ways. The nominal pitch was calculated by adding the pin cladding diameter to the spacer wire diameter [14]. This represents the closest together that the pins could get. However, one could also assume the exterior pins' spacer wires touched the interior wall of the subassembly sleeve and use the sleeve dimensions to calculate the pitch [25]. This would be the largest possible pin pitch. For the MCUQ, a uniform distribution PDF was assumed to be bounded by these two pitches, which varied by about $1.8 \mathrm{~mm}$.

\subsubsection{BISON Models}

The BISON Models group included inputs to BISON models and correlations. The inputs in this group are used in BISON physics models and are less likely to be simulation-specific than the inputs in the other groups.

The cladding creep multiplier was applied to the D9 cladding creep model. The PDF was estimated by entering IFR-1 conditions and nominal benchmark predictions into a correlation in the Nuclear Systems Materials Handbook (NSMH) [27]. However, the NSMH was marked Applied Technology and Foreign National Access Restricted, so the correlation cannot be shown or discussed here.

The cladding CTE and swelling uncertainties were calculated in their models' documentation [28,29], which the authors of this report greatly appreciate. The fuel CTE multiplier standard deviation was calculated from experimental measurements collected by Middlemas and Janney [23]. 
It was difficult to estimate the PDF for the EPF. The nominal value of $200 \mathrm{MeV}\left(3.2 \times 10^{-11} \mathrm{~J}\right)$ has become so ubiquitous that many sources do not even cite it $[34,35]$, making the original source of the value difficult to find. However, the authors were able to get two estimates. First, Shultis and Faw list a range of 198-204 MeV [35]. However, no data or references were cited for that range. Second, Sher and Beck measured the individual EPFs for 16 isotopes [30]. They found energies per fission of $202 \mathrm{MeV}$ for ${ }^{235} \mathrm{U}$ and $207 \mathrm{MeV}$ for ${ }^{239} \mathrm{Pu}$, both higher than the standard estimate. The range for all isotopes ranged from 196 to $218 \mathrm{MeV}$. It was decided to use the standard $200 \mathrm{MeV}$ as the mean and apply a simple standard deviation of $7 \mathrm{MeV}\left(0.1 \times 10^{-11} \mathrm{~J}\right)$. This way, the nominal predictions are consistent with other BISON simulations and the uncertainty can be easily traced back to experimental data. However, it is likely that this standard deviation is larger than necessary.

BISON's fuel gaseous swelling model was developed specifically for BISON. The model's developers took a model from Olander [34] and applied several assumptions to reduce it to an analytical equation. At the time of this study, confidence intervals had not been estimated for this model, so the PDF assumed a high uncertainty.

BISON's solid swelling coefficient of 1.5 (\% strain/\% burnup) was calculated by Ogata and Yookoo [31]. That paper also referenced other works that had found coefficients of 1.2 and 1.7. The standard deviation of those three values is $0.5 \%$. The normal distribution was then truncated so the coefficient was always greater than 0 .

BISON's FGR model is a semi-empirical correlation based on data recorded by Hofman et al. [32]. The Hofman et al. data had significant noise, which was used to estimate a standard deviation of $3 \%$.

The equation that calculates the thermal conductivity of the $\mathrm{Na}$ in the gap and plenum was developed by Fink and Leibowitz [33]. They also calculated a temperature dependent confidence interval:

$$
\begin{gathered}
k(T)=\left[124.67-0.11381 T+5.5226 \times 10^{-5} T^{2}-1.1842 \times 10^{-8} T^{3}\right] \times \\
{\left[1+\alpha \frac{-7.25+0.0175 T}{100}\right]}
\end{gathered}
$$

where $k$ was the thermal conductivity $\left(\mathrm{W} \mathrm{m}^{-1} \mathrm{~K}^{-1}\right), T$ was the absolute temperature (K), and $\alpha$ was the gap thermal conductivity prefactor.

\subsection{LEGACY CONFIDENCE INTERVAL ESTIMATES}

In addition to the benchmark inputs. The confidence intervals of legacy PIE measurements and calculations also needed to be established. Peak and average burnup were calculated with a fairly straightforward formula $[3,34]$ :

$$
\beta_{n}=\frac{\dot{F} \Delta t}{N_{f}^{0}}
$$

where $\beta_{n}$ was the burnup (-), $\dot{F}$ was the fission rate density (fissions $\mathrm{m}^{-3} \mathrm{~s}^{-1}$ ), $\Delta t$ was the discrete timestep size (s), and $N_{f}^{0}$ was the fissile atom density of the fuel (atoms $\mathrm{m}^{-3}$ ). Since the formula was straightforward, the simplest way to approximate the uncertainty was to propagate the EPF confidence interval through Eq. (9), using the fission rate definition 


$$
\dot{F}=\frac{q^{\prime \prime \prime}}{E_{f}}
$$

where $q^{\prime \prime \prime}$ is the volumetric heat generation rate $\left(\mathrm{J} \mathrm{m}^{-3} \mathrm{~s}^{-1}\right)$ and $E_{f}$ is the EPF $\left(\mathrm{J}_{\text {fission }}{ }^{-1}\right)$. The relative uncertainty of the burnup, $u_{b}$, depends on the uncertainty of the EPF, $u_{e}$, according to,

$$
u_{b}=\frac{\beta_{n}\left(E_{f}+u_{e}\right)-\beta_{n}\left(E_{f}\right)}{\beta_{n}\left(E_{f}\right)}=\frac{E_{f}}{E_{f}+u_{e}}-1
$$

Using $u_{e}=2 \sigma$ from Table 4 yields a relative confidence interval of about $\pm 6.3 \%$ of the legacy burnup.

The legacy coolant outlet temperature and peak cladding temperature were both calculated using the SUPERENERGY-2 (SE-2) code [14]. Yang and Yacout found that in validation cases, SE-2 coolant temperature predictions had a maximum error of $20 \mathrm{~K}$ [36]. Therefore, the confidence intervals for both temperatures were set to $\pm 20 \mathrm{~K}$.

Cladding radial dilation was measured during PIE using laser profilometry at five different angles. This method was very accurate and had negligible uncertainty. However, dilation was often nonuniform, as the cross sections of the pins could become elliptical. The legacy average dilation was calculated by averaging the profilometry measurements. This likely introduced some error, so a relatively small confidence interval of $\pm 0.02 \%$ was assumed.

Fuel axial elongation was measured by taking neutron radiography images of the fuel pins next to rulers. In some experiments, these measurements had very high uncertainties because of fuel foaming [37]. However, the blankets prevented foam development in IFR-1, so the measurement uncertainty should be very low. The smallest markings on the rulers were $1 / 50$ of an inch $(0.51 \mathrm{~mm})$, so that was the confidence interval assumed for this work.

FGR was calculated partially based on plenum pressure. Plenum pressure was measured using INL's Gas Assay Sample and Recharge system, which had a pressure/volume combined confidence interval of $\pm 5 \%$ [38]. Based on this, the plenum pressure and FGR confidence intervals were assumed to be $\pm 5 \%$.

\subsection{SIMULATION SETUP}

A template input file was created for each composition. The variables followed the same convention as those in Section 2.2. The BISON@ORNL repository was used again [19]. One nominal simulation was performed, and then each input was randomly sampled from the PDFs listed in Table 4 . The input values for each simulation were stored in CSV files. Predictions were measured at times corresponding to the legacy values for direct comparisons.

A Python script was used for simulation postprocessing. Since MCUQ is a stochastic method, the exact results had some noise. To partially mitigate this, the $95 \%$ confidence interval of each uncertainty was calculated. For the first two sets of simulations (120 simulations each), the fourth highest and fourth lowest values of each composition were reported as the maximum and minimum uncertainties. For the last set of simulations with all three uncertainty groups (200 simulations), the sixth highest and sixth lowest values were used. 


\subsection{RESULTS}

All the predictions from the legacy/predictions comparisons were averaged. The resulting $95 \%$ confidence intervals are shown in Table 5. The first column shows the nominal predicted value averaged across all measurement times and all three compositions. The second column shows the relative confidence interval for the GPA case. As an example, the average nominal peak burnup was $5.8 \%$ with a GPA confidence interval of $5.65 \%$ to $5.99 \%(-2.6 /+3.2$ relative change $)$. The third column shows the confidence intervals for the combined GPA and Experimental case. The relative effect of the Experimental uncertainty can be found by subtracting the GPA value from the GPA and Experimental value. The right-most column with all three groups shows the overall uncertainty. All three uncertainty groups appear to contribute to peak and average burnup relatively equally. By contrast, most of the uncertainty in coolant outlet and peak cladding temperature are due to the addition of the Experiment group. The confidence interval lower boundary extends much farther than the upper boundary.

Table 5. Average 95\% BISON confidence intervals for each of the eight predictions. The predictions were averaged over all legacy/prediction comparisons. For each prediction, the average nominal BISON value is recorded in SI units. Then for each of the three cases, lower and upper bounds of the relative uncertainties are shown.

\begin{tabular}{|c|c|c|c|c|c|c|c|}
\hline \multirow[b]{2}{*}{ Value } & \multirow{2}{*}{ 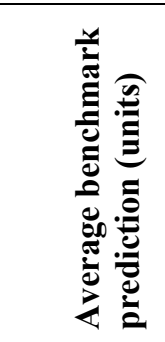 } & \multicolumn{6}{|c|}{$\begin{array}{c}\text { 95\% confidence interval low/high boundaries } \\
(\%)\end{array}$} \\
\hline & & \multicolumn{2}{|c|}{ 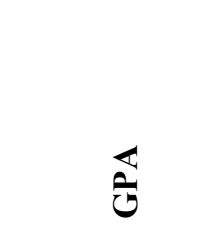 } & \multicolumn{2}{|c|}{ 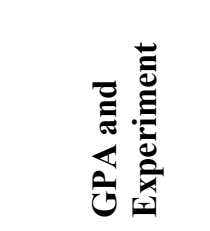 } & \multicolumn{2}{|c|}{ 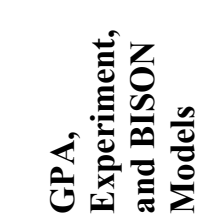 } \\
\hline Peak burnup & $5.8($ at $\%)$ & $-2.6 /$ & 3.2 & $-5.1 /$ & 7.4 & $-8.2 /$ & 11.4 \\
\hline Average Burnup & $4.7($ at $\%)$ & $-2.6 /$ & 3.2 & $-5.5 /$ & 6.0 & $-8.4 /$ & 9.7 \\
\hline Coolant outlet temperature & $853.6(\mathrm{~K})$ & $-0.2 /$ & 0.1 & $-18.4 /$ & 0.8 & $-18.1 /$ & 2.1 \\
\hline Peak cladding temperature & $838.4(\mathrm{~K})$ & $-0.1 /$ & 0.1 & $-15.3 /$ & 1.5 & $-14.6 /$ & 3.1 \\
\hline Fuel elongation & $5.0(\%)$ & $-38.1 /$ & 60.6 & $-37.6 /$ & 70.1 & $-38.4 /$ & 162.0 \\
\hline Peak cladding dilation & $5.3(\%)$ & $-7.3 /$ & 10.0 & $-74.0 /$ & 22.0 & $-74.5 /$ & 32.4 \\
\hline Plenum pressure & $2.6(\mathrm{MPa})$ & $-2.3 /$ & 1.8 & $-5.3 /$ & 11.5 & $-38.1 /$ & 28.2 \\
\hline FGR & $77.1(\%)$ & $-0.2 /$ & 0.2 & $-1.5 /$ & 0.7 & $-45.2 /$ & 9.7 \\
\hline
\end{tabular}

Almost all the fuel elongation confidence interval's lower boundary came from the GPA. However, a significant portion of the upper boundary came from BISON Models. The cladding dilation confidence interval lower boundary was primarily caused by the Experiment group, but all three groups contributed to the upper boundary. BISON Models was the primary contributor to the plenum pressure confidence interval, but the GPA also contributed. The only significant uncertainty for FGR came from BISON Models.

Several benchmark confidence intervals were reduced as additional groups were added to the MCUQ studies, including the coolant outlet temperature, peak cladding temperature, and fuel elongation. The exact cause of this is unknown, but the simplest explanation is that these were random variations caused by the stochastic nature of MCUQ that are not replicable.

Benchmark predictions and overall confidence intervals are plotted against legacy values and confidence intervals in Figure 1. Each point represents a nominal benchmark prediction and corresponding legacy value. The box around each point represents the confidence intervals. The points and boxes are colored according to fuel composition. Plots 1.a) and 1.b) show the peak and average burnup, respectively. The points tend to fall near the diagonal, suggesting relatively high accuracy. The boxes have low aspect ratios 
and grow as burnup increases, suggesting that the legacy calculations and benchmark predictions have similar confidence intervals.
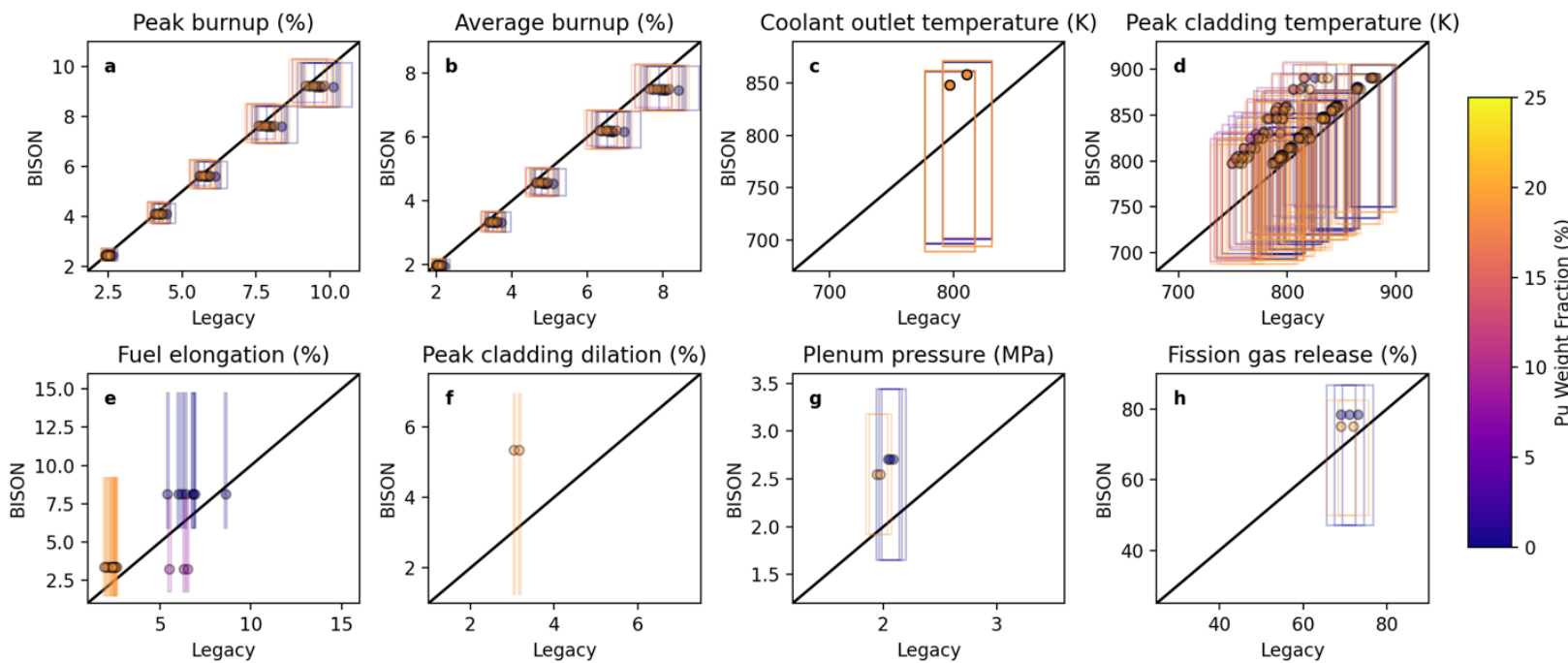

Figure 1. Benchmark predictions plotted and corresponding legacy values for all legacy values and all compositions. The values shown include a) peak burnup, b) average burnup, c) coolant outlet temperature, d) peak cladding temperature, e) fuel elongation, f) peak cladding dilation, g) plenum pressure, and h) FGR. Points represent benchmark nominal predictions and reported legacy values. The boxes around the points represent the predicted and legacy confidence intervals. Points and boxes are colored according to fuel composition.

Plots 1.c) and 1.d) show the coolant outlet and peak cladding temperature, respectively. There were far more legacy cladding temperature calculations than coolant outlet temperature calculations in the benchmark $[6,14]$. Plot $1 . e)$ shows the fuel elongation values. The legacy confidence intervals were very narrow, but the predicted confidence intervals were significant. Plot 1.f) shows the peak cladding dilation. Only two legacy values were available for comparison, both from 19Pu pins. Plots 1.g) and 1.h) show plenum pressure and FGR, respectively. In both cases, the confidence interval was smaller for $19 \mathrm{Pu}$ pins than for $00 \mathrm{Pu}$ pins.

Two features of Figure 1 need to be discussed. First, only one out of 323 total data points failed to cross the diagonal line: the left-most U-10Zr data point in Plot 1.e). The benchmark predictions were accurate within their $95 \%$ confidence intervals $99.7 \%$ of the time. Second, five of the benchmark predictions had skewed confidence intervals. Coolant outlet temperature, peak cladding temperature, peak cladding dilation, and FGR all had lower boundaries on their confidence intervals that were much larger than their upper boundaries. Fuel elongation had a larger upper boundary on its confidence interval. This was somewhat unexpected because most of the inputs used symmetrical distributions centered at the nominal values. Only the pin pitch and the fuel gaseous swelling multipliers were asymmetrical. Either these two inputs had outsized effects on the predictions or there were some nonlinear relationships between one or more other inputs and benchmark predictions.

Histograms of the benchmark predictions overall uncertainty distributions for the three fuel compositions are shown in Figures 2-4. Figure 2 shows the distributions for the $00 \mathrm{Pu}$ pin, Figure 3 shows them for the $08 \mathrm{Pu}$ pin, and Figure 4 shows them for the 19Pu pin. All the histograms have 15 bins and are normalized so that the area under the curve is equal to 1 . There appear to be no significant differences in the distributions between compositions. In all cases, the temperatures reflect the maximum temperature reached during the simulation, whereas the other values are at ends of the benchmark after reactor cooldown, which were designed to match the experimental PIE conditions [6]. 
U-00Pu-10Zr
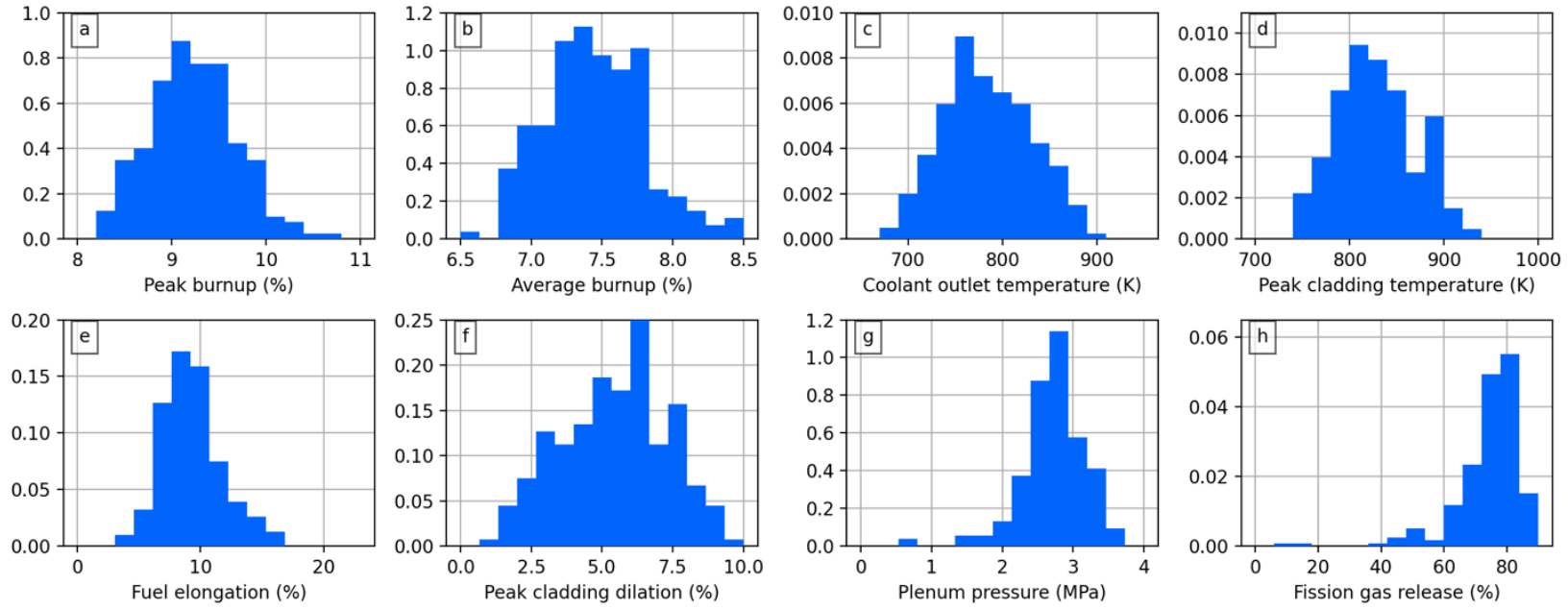

Figure 2. Uncertainty distribution for the eight benchmark predictions for the 00Pu case. The distributions

include a) peak burnup at simulated PIE conditions, b) average burnup at PIE, c) maximum coolant outlet temperature during the simulation, d) maximum cladding temperature during the simulation, e) fuel elongation at

PIE, f) peak cladding dilation at PIE, g) plenum pressure at PIE, and h) FGR at PIE.

U-08Pu-10Zr
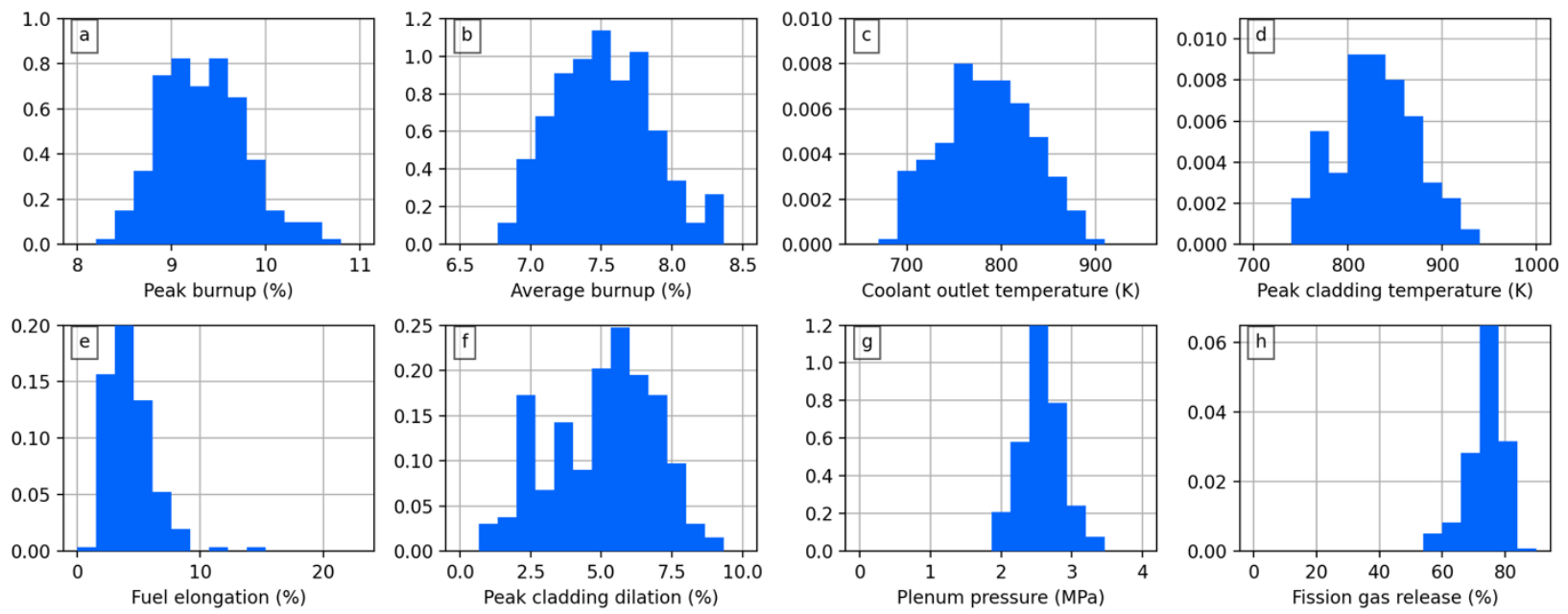

Figure 3. Uncertainty distribution for the eight benchmark predictions for the $08 \mathrm{Pu}$ case. The distributions include a) peak burnup at simulated PIE conditions, b) average burnup at PIE, c) maximum coolant outlet temperature during the simulation, d) maximum cladding temperature during the simulation, e) fuel elongation at PIE, f) peak cladding dilation at PIE, g) plenum pressure at PIE, and h) FGR at PIE. 
U-19Pu-10Zr
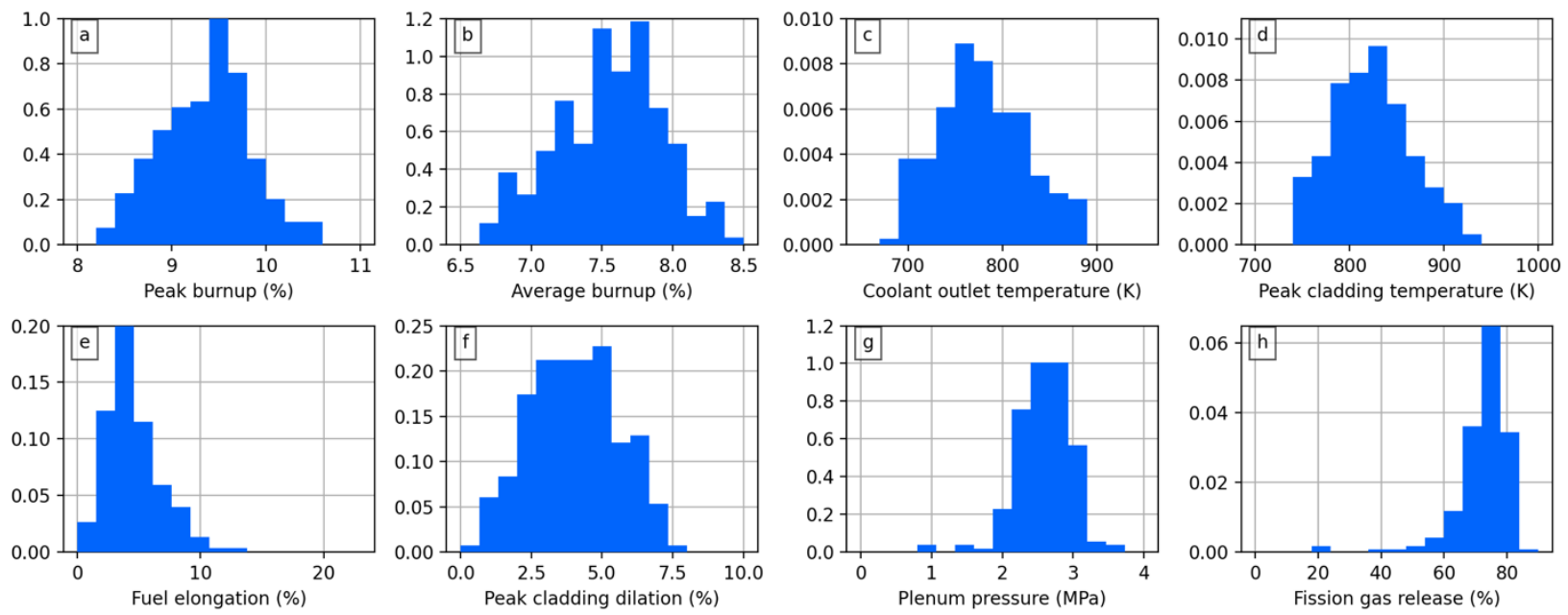

Figure 4. Uncertainty distribution for the eight benchmark predictions for the 19Pu case. The distributions include a) peak burnup at simulated PIE conditions, b) average burnup at PIE, c) maximum coolant outlet temperature during the simulation, d) maximum cladding temperature during the simulation, e) fuel elongation at PIE, f) peak cladding dilation at PIE, g) plenum pressure at PIE, and h) FGR at PIE.

Peak and average burnup, coolant outlet and peak cladding temperature, and peak cladding dilation all appeared to have normal distributions. Fuel elongation had a right-skewed distribution and FGR had a left-skewed distribution. Plenum pressure appeared to be left-skewed for 00Pu and 19Pu but followed a normal distribution for $08 \mathrm{Pu}$. This may represent a slight skew, but there is too much noise in the figures to draw a firm conclusion. The skewed distributions shown in Figures 2-4 help explain the asymmetric confidence intervals in Figure 1 for fuel axial elongation, peak cladding dilation, and FGR, since those distributions are all skewed. However, the figures do not explain the asymmetry in the temperature confidence intervals or in the peak cladding dilation confidence interval.

\subsection{DISCUSSION}

The confidence intervals of most benchmark predictions were quite large. The average coolant outlet temperature confidence interval included a range of over $170 \mathrm{~K}$. The peak cladding temperature's range covered over $150 \mathrm{~K}$. The fuel elongation confidence interval upper boundary was $160 \%$ higher than the nominal prediction. The only benchmark uncertainties that closely matched the legacy uncertainties were peak and average burnup. This is not surprising since BISON used the same function to determine burnup as legacy calculations and the legacy confidence intervals were based on BISON input uncertainties.

According to Table 5, simulating individual pins rather than nominal pins would significantly reduce uncertainties in burnup and fuel elongation predictions. Likewise, more accurate experimental data from this experiment, other benchmarks, or future experiments could reduce burnup, temperature, and cladding dilation uncertainties. Improved BISON models could reduce uncertainties of burnup, cladding dilation, plenum pressure, and FGR predictions.

One natural question that arises is which inputs, specifically, are the sources of these uncertainties. One way to examine this question without significantly more MCUQ studies is to compare the three uncertainty group confidence intervals to the sensitivities in Section 2.3. Burnups were most sensitive to fuel and blanket radius (GPA), fuel density (GPA), EPF (BISON Models), and LHGR multiplier (Experiment). Although burnup was clearly more sensitive to GPA than the other groups, the fuel and blanket radius and fuel density also had narrower PDFs than the inputs in the other groups. This could explain the uniform uncertainty contributions from the three groups. 
The temperature predictions were most sensitive to pin pitch and $\mathrm{Na}$ inlet temperature, both of which were from the Experiment group. Additionally, recall that Figure 1 shows that the nominal predictions were at the edge of the uncertainty distributions for the temperatures, but Figures 2-4 show that the uncertainty distributions were symmetrical. The high sensitivity to pin pitch could explain this result because the nominal value of the pin pitch was on one end of its uncertainty distribution.

Fuel elongation was highly sensitive to the fuel and blanket radius (GPA). However, the sensitivities do not explain the uncertainty associated with the BISON models group. To help identify that relationship, the fuel elongation predictions were plotted against all 25 inputs for the U-19Pu-10Zr composition in Figure 5. Figure 5 shows the nominal simulation in black, MCUQ simulations in blue, and a linear leastsquares fit as a black line. The coefficient of determination $\left(\mathrm{r}^{2}\right)$ and the total change $(\Delta y)$ for each trendline are also shown. Plots 5.q)-5.y) show inputs from the BISON model group. The strongest of these correlations were with the fuel solid swelling coefficient (5.w) and the fuel gaseous swelling multiplier (5.v). However, the fuel gaseous swelling multiplier correlation does not appear to be linear, so the $r^{2}$ value did not accurately capture the strength of the correlation. 
U-19Pu-10Zr: Fuel elongation (\%)
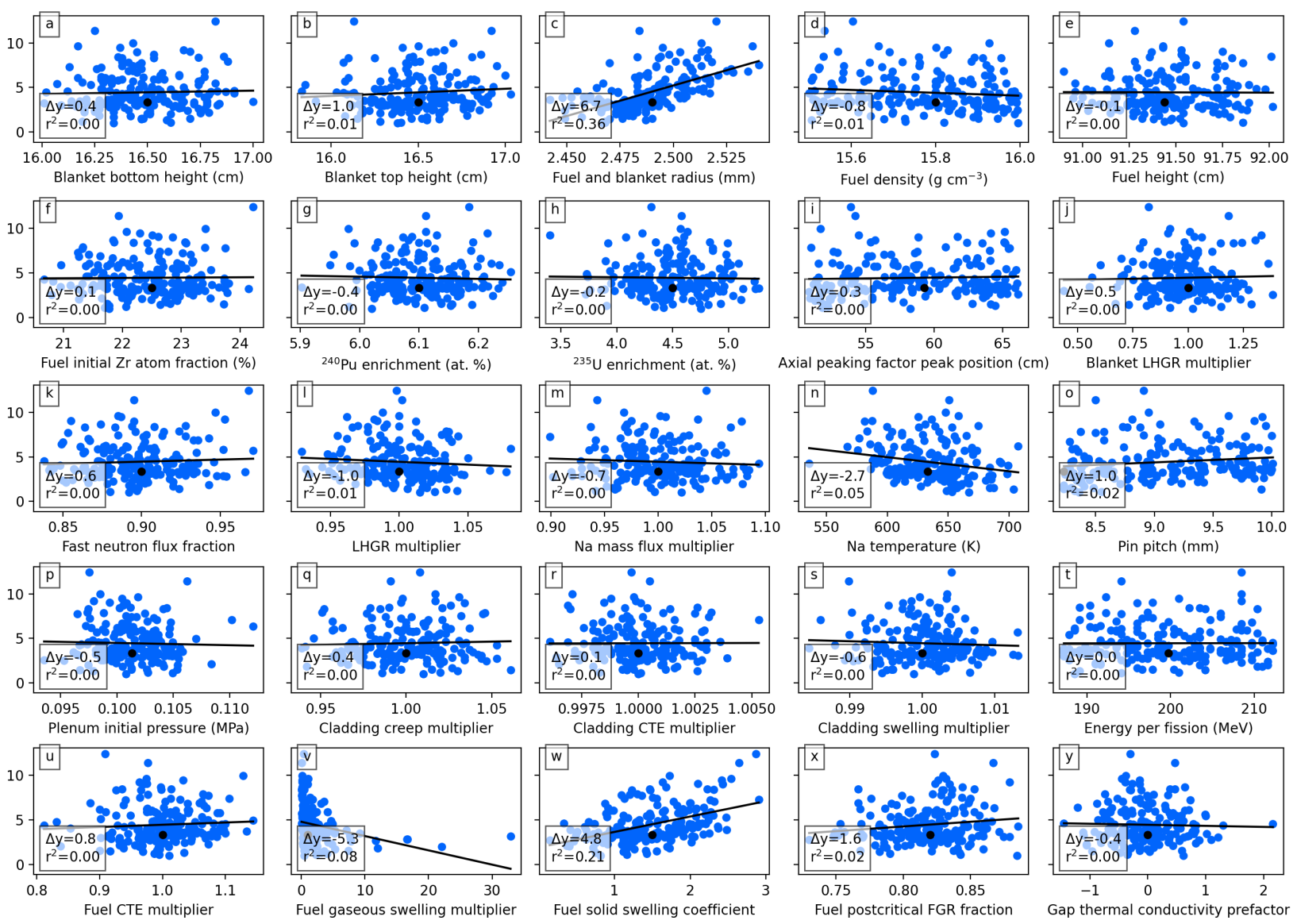

Figure 5. 200 MCUQ benchmark predictions of fuel axial elongation for U-19Pu-10Zr fuel. The predictions are plotted against each of the 25 inputs from Table 4: a) blanket bottom height, b) blanket top height, c) fuel and blanket radius, d) fuel density, e) fuel height, f) fuel initial $\mathrm{Zr}$ atom fraction, g) ${ }^{240} \mathrm{Pu}$ enrichment, h) ${ }^{235} \mathrm{U}$ enrichment, i) axial peaking factor peak position, j) blanket LHGR multiplier, k) fast neutron flux fraction, 1) LHGR multiplier,

m) Na mass flux multiplier, n) Na inlet temperature, o) pin pitch, p) plenum initial pressure, q) cladding creep multiplier, r) cladding CTE multiplier, s) cladding swelling multiplier, t) energy per fission, $u$ ) fuel CTE multiplier, v) fuel gaseous swelling multiplier, w) fuel solid swelling coefficient, $x$ ) fuel postcritical FGR fraction, and y) gap thermal conductivity prefactor. The nominal prediction is shown in black. A linear least-squares trendline was fit to each correlation. The coefficient of determinant $\left(\mathrm{r}^{2}\right)$ and total change $(\Delta y)$ of each trendline is shown on the plot.

The peak cladding radial dilation was most sensitive to the fuel and blanket radius (GPA), Na inlet temperature (Experiment), LHGR multiplier (Experiment), EPF (BISON models), fuel density (GPA), fast neutron flux fraction (Experiment), pin pitch (Experiment), and ${ }^{235} \mathrm{U}$ enrichment (GPA). It was sensitive to more inputs than any other prediction (see Table 2), which likely explains why the confidence interval upper boundary increases more or less uniformly with each group. However, the lower boundary was introduced almost entirely by the Experiment group. Such a one-sided contribution suggests that the pin pitch may have once again played an important role.

Plenum pressure and FGR confidence intervals were both strongly associated with the BISON models group. Plenum pressure was highly sensitive to fuel height (GPA) and fuel and blanket radius (GPA), whereas FGR had no high sensitivities greater than 1 (see Table 2). Sensitivities alone do not explain the uncertainties associated with BISON models. Thus, the individual simulation results for FGR are shown in Figure 6 in a similar method to Figure 5. According to Plot 6.v), the fuel gaseous swelling multiplier had the strongest correlation. However, like Figure 5.v), it had a nonlinear correlation, so the coefficient of determination underestimated its strength. Not only could this explain why FGR appeared not to be 
sensitive to the fuel gaseous swelling multiplier in the sensitivity study (the variation was not large enough to reflect the nonlinear nature of the relationship), but it also explains why the confidence interval was skewed (nonlinear correlation so that input variation in one direction did not affect the prediction).
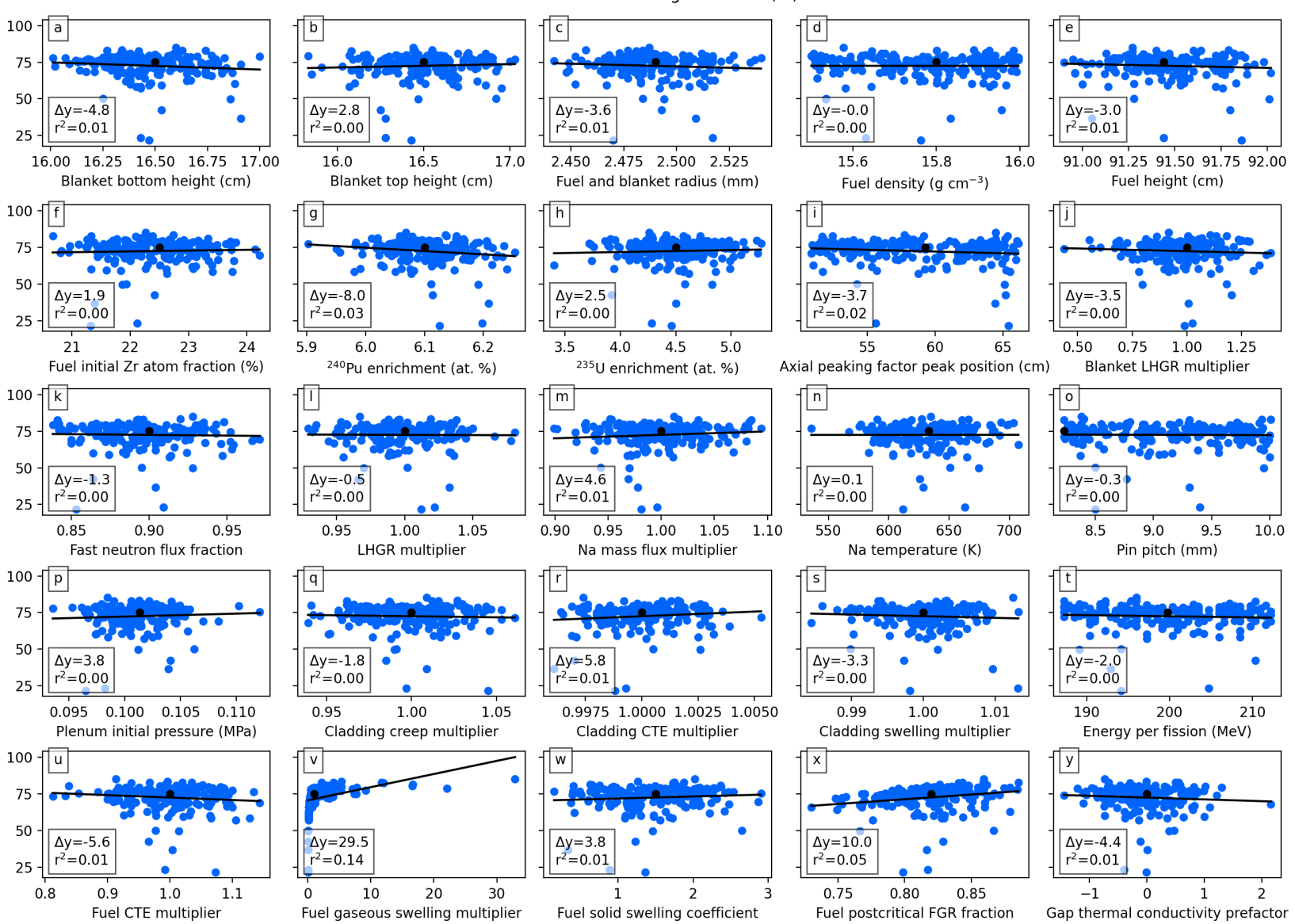

Figure 6. 200 MCUQ benchmark predictions of FGR for U-19Pu-10Zr fuel. The predictions are plotted against each of the 25 inputs from Table 4: a) blanket bottom height, b) blanket top height, c) fuel and blanket radius, d) fuel density, e) fuel height, f) fuel initial $\mathrm{Zr}$ atom fraction, g) ${ }^{240} \mathrm{Pu}$ enrichment, h) ${ }^{235} \mathrm{U}$ enrichment, i) axial peaking factor peak position, j) blanket LHGR multiplier, $\mathrm{k}$ ) fast neutron flux fraction, 1) LHGR multiplier, $\mathrm{m}$ ) Na mass flux multiplier, n) Na inlet temperature, o) pin pitch, p) plenum initial pressure, q) cladding creep multiplier, r) cladding CTE multiplier, s) cladding swelling multiplier, t) energy per fission, u) fuel CTE multiplier, v) fuel gaseous swelling multiplier, w) fuel solid swelling coefficient, $\mathrm{x}$ ) fuel postcritical FGR fraction, and y) gap thermal conductivity prefactor. The nominal result is shown in black. A linear least-squares trendline was fit to each correlation. The coefficient of determinant $\left(\mathrm{r}^{2}\right)$ and total change $(\Delta \mathrm{y})$ of each trendline is shown on the plot.

This finding suggests that the FGR prediction's confidence interval was caused primarily by uncertainty in the fuel swelling model. Furthermore, since FGR led to additional gas in the plenum, the fuel gas swelling multiplier was also a likely contributor to the plenum pressure confidence interval.

All the inputs and BISON simulation predictions were plotted in the manner of Figures 5 and 6 . However, for the sake of brevity they are not included in this report. Instead, their $\mathrm{r}^{2}$ values are summarized in Table 6. $\mathrm{r}^{2}$ values greater than 0.01 are in bold, whereas values greater than 0.05 are highlighted in dark green. Comparisons between the table and inputs identified as important based on sensitivities suggested that 0.05 was a reasonable cutoff for identifying important sources of uncertainty. Using this cutoff, 10 inputs were significant sources of uncertainty. These are summarized in Table 7. 
Table 6. Coefficients of determination for all linear correlations between inputs and benchmark predictions. Coefficients are averaged across the three compositions. Coefficients greater than 0.01 are in bold. Coefficients greater than 0.05 are highlighted in dark green.

\begin{tabular}{|c|c|c|c|c|c|c|c|c|c|}
\hline \multirow[b]{2}{*}{ Group } & \multirow[b]{2}{*}{ Input } & \multicolumn{8}{|c|}{ Average coefficient of determination $\left(r^{2}\right)$} \\
\hline & & 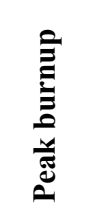 & 总 & 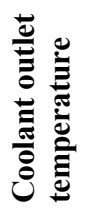 & 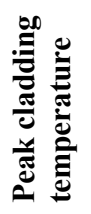 & 厄 & 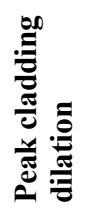 & 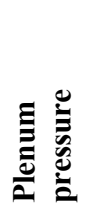 & $\underset{\bigcup}{\mathfrak{J}}$ \\
\hline \multirow{8}{*}{ 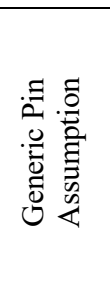 } & Blanket bottom height & 0.001 & 0.002 & 0.006 & 0.006 & 0.007 & 0.012 & 0.010 & 0.018 \\
\hline & Blanket top height & 0.004 & 0.003 & 0.004 & 0.005 & 0.005 & 0.000 & 0.003 & 0.005 \\
\hline & Fuel and blanket radius & 0.089 & 0.096 & 0.002 & 0.002 & 0.324 & 0.004 & 0.003 & 0.003 \\
\hline & Fuel density & 0.057 & 0.058 & 0.009 & 0.009 & 0.005 & 0.021 & 0.002 & 0.001 \\
\hline & Fuel height & 0.002 & 0.003 & 0.001 & 0.002 & 0.008 & 0.006 & 0.000 & 0.006 \\
\hline & Fuel initial $\mathrm{Zr}$ atom fraction & 0.006 & 0.003 & 0.003 & 0.002 & 0.002 & 0.001 & 0.001 & 0.008 \\
\hline & ${ }^{240} \mathrm{Pu}$ enrichment & 0.000 & 0.005 & 0.000 & 0.000 & 0.001 & 0.000 & 0.018 & 0.028 \\
\hline & ${ }^{235} \mathrm{U}$ enrichment & 0.003 & 0.002 & 0.004 & 0.004 & 0.001 & 0.002 & 0.008 & 0.004 \\
\hline \multirow{8}{*}{ 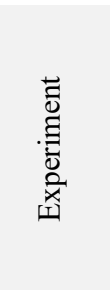 } & Axial peaking factor peak position & 0.056 & 0.007 & 0.012 & 0.008 & 0.001 & 0.007 & 0.010 & 0.012 \\
\hline & Blanket LHGR multiplier & 0.008 & 0.005 & 0.015 & 0.013 & 0.005 & 0.013 & 0.023 & 0.019 \\
\hline & Fast neutron flux fraction & 0.002 & 0.005 & 0.007 & 0.007 & 0.003 & 0.049 & 0.013 & 0.000 \\
\hline & LHGR multiplier & 0.332 & 0.348 & 0.032 & 0.045 & 0.008 & 0.118 & 0.024 & 0.003 \\
\hline & Na mass flux multiplier & 0.012 & 0.016 & 0.008 & 0.008 & 0.003 & 0.006 & 0.011 & 0.010 \\
\hline & $\mathrm{Na}$ inlet temperature & 0.006 & 0.009 & 0.368 & 0.458 & 0.034 & 0.586 & 0.042 & 0.006 \\
\hline & Pin pitch & 0.005 & 0.004 & 0.567 & 0.459 & 0.025 & 0.135 & 0.005 & 0.004 \\
\hline & Plenum initial pressure & 0.001 & 0.001 & 0.004 & 0.003 & 0.012 & 0.003 & 0.001 & 0.007 \\
\hline \multirow{9}{*}{$\begin{array}{l}\frac{n}{0} \\
\frac{0}{0} \\
\sum_{0} \\
0 \\
0 \\
0\end{array}$} & Cladding creep multiplier & 0.001 & 0.002 & 0.001 & 0.001 & 0.014 & 0.003 & 0.013 & 0.017 \\
\hline & Cladding CTE multiplier & 0.001 & 0.001 & 0.003 & 0.004 & 0.001 & 0.005 & 0.006 & 0.010 \\
\hline & Cladding swelling multiplier & 0.008 & 0.009 & 0.003 & 0.003 & 0.003 & 0.006 & 0.004 & 0.005 \\
\hline & Energy per fission & 0.495 & 0.574 & 0.009 & 0.008 & 0.002 & 0.030 & 0.096 & 0.003 \\
\hline & Fuel CTE multiplier & 0.002 & 0.002 & 0.017 & 0.015 & 0.011 & 0.007 & 0.002 & 0.009 \\
\hline & Fuel gaseous swelling multiplier & 0.004 & 0.003 & 0.002 & 0.002 & 0.081 & 0.003 & 0.307 & 0.210 \\
\hline & Fuel postcritical FGR fraction & 0.003 & 0.002 & 0.005 & 0.004 & 0.012 & 0.003 & 0.017 & 0.062 \\
\hline & Fuel solid swelling coefficient & 0.000 & 0.001 & 0.002 & 0.002 & 0.226 & 0.004 & 0.028 & 0.004 \\
\hline & Gap thermal conductivity prefactor & 0.000 & 0.001 & 0.002 & 0.002 & 0.005 & 0.001 & 0.006 & 0.005 \\
\hline
\end{tabular}

Table 7. Summary of benchmark inputs with coefficients of determination greater than 0.05 .

\begin{tabular}{lll}
\hline Group & Input & Benchmark predictions \\
\hline Generic Pin & Fuel and blanket radius & Peak burnup, average burnup, fuel axial elongation \\
Assumption & Fuel density & Peak burnup, average burnup \\
& $\begin{array}{l}\text { Axial peaking factor peak } \\
\text { position }\end{array}$ & Peak burnup \\
& LHGR multiplier & Peak burnup, average burnup, cladding dilation \\
Experiment & Na inlet temperature & $\begin{array}{l}\text { Coolant outlet temperature, peak cladding } \\
\text { temperature, fuel axial elongation }\end{array}$ \\
& Pin pitch & Coolant outlet temperature, peak cladding \\
& Energy per fission & temperature, fuel axial elongation \\
& Fuel gaseous swelling & Peak burnup, average burnup, plenum pressure \\
BISON & multiplier & Fuel elongation, plenum pressure, FGR \\
Models & Fuel postcritical FGR fraction & FGR \\
& Fuel solid swelling coefficient & Axial elongation \\
\hline
\end{tabular}

The largest coefficient of determination is between the Na inlet temperature and the peak cladding dilation (0.586). It is a significantly stronger correlation than that between fuel and blanket radius and the 
fuel elongation (0.324), which was the most sensitive relationship established by the sensitivity study. There are also two other correlations with coefficients of determination greater than 0.5: energy per fission to average burnup (0.574) and pin pitch to coolant outlet temperature (0.586). In fact, pin pitch has three strong correlations, which is quite significant for an input with a confidence interval of less than 2 $\mathrm{mm}$.

A comparison of Tables 6 and 7 with the inputs identified based on sensitivities and group confidence intervals yielded good agreement for all benchmark predictions except cladding dilation. Cladding dilation was sensitive to eight inputs spanning all three groups, which was the most of any benchmark prediction. However, it only had three strong coefficients of determination, all in the Experiment group. There are two possible causes of this. First, an input with a high sensitivity but low uncertainty may not significantly contribute to the confidence intervals. Second, a prediction that is dependent on many inputs has weaker correlations with each individual input compared to a prediction that is dependent on only one input. Both causes likely contributed to the disagreement between sensitivities and coefficients for the cladding dilation prediction.

\section{CONCLUSIONS AND FUTURE WORK}

A sensitivity study and an uncertainty quantification were performed on three generic pins of a BISON benchmark based on the IFR-1 experiment. The sensitivity analysis varied 49 independent inputs and tracked the changes in nine benchmark predictions that correspond to PIE data and legacy calculations. Of the 49 inputs, 25 were identified as potentially strong enough to contribute to overall uncertainty, and 10 had sensitivities greater than 1 .

Eight benchmark prediction confidence intervals were estimated using MCUQ. Uncertainty distributions for the 25 inputs were estimated from the literature based on some combination of raw experimental data, uncertainties included in models, comparisons between models, and engineering judgment. Inputs were randomly sampled from their distributions and used to populate a BISON input file template. Confidence intervals were estimated based on benchmark predictions' responses to the inputs.

The $95 \%$ confidence intervals for benchmark predictions were compared to their corresponding legacy values and associated confidence intervals. $99.7 \%$ of the predictions matched the legacy values when confidence intervals were accounted for. However, this near-perfect match is largely caused by significant uncertainties in the benchmark predictions.

Ten inputs were identified that contributed significantly to the uncertainties of one or more benchmark predictions. Two of the input uncertainties were associated with the GPA. Four of the input uncertainties were associated with uncertainties in the experimental conditions that could be mitigated through development of additional benchmarks or by better recording conditions in future experiments. The last four inputs were associated with BISON models: energy per fission, fuel gaseous swelling multiplier, fuel postcritical FGR fraction, and fuel solid swelling coefficient. Reducing the uncertainties in these models may require collecting more experimental data or additional model development.

Future work should include a more detailed literature review to reduce the uncertainty in the average EPF and separately quantify the uncertainties of the postcritical FGR fraction and the fuel FGR terminating porosity. Future modeling work should focus on performing sensitivity analyses and UQs on additional benchmarks. The X430 benchmark is a good candidate because it has already been developed based on individual pins [8]. Similar analyses can be performed on other benchmarks as they are developed [38]. Performing analyses on multiple benchmarks may help mitigate uncertainty caused by benchmark 
assumptions and experimental conditions, since the experimental conditions and assumptions vary for each benchmark.

At this time, very little can be done to improve the accuracy of BISON predictions because the predictions were within the confidence intervals $99.7 \%$ of the time, and a significant portion of the uncertainty was not associated with BISON models. Therefore, future BISON model development should focus on quantifying the uncertainty of the fuel gaseous swelling model and reducing uncertainties in the solid swelling and fission gas release models.

\section{REFERENCES}

[1] J. Hu, J.J. Powers, A.J. Oaks, F. Heidet, Preliminary Fuel Performance Assessment of Proposed Versatile Test Reactor Driver Fuel Concept for Normal Operating Conditions Using BISON, Oak Ridge National Laboratory, Oak Ridge, Tennessee, 2019.

[2] J. Hu, J.J. Powers, A.J. Oaks, F. Heidet, Preliminary Fuel Performance Assessment of Proposed Versatile Test Reactor Driver Fuel Concept for Off-Normal Operating Conditions Using BISON, Oak Ridge National Laboratory, Oak Ridge, Tennessee, 2020.

[3] BISON A Finite Element-Based Nuclear Fuel Performance Code, (n.d.). https://mooseframework.inl.gov/bison/ (accessed May 19, 2021).

[4] K.M. Cunningham, J.J. Powers, R.A. Lefebvre, Modeling the IFR-1 Experiment: A BISON Metallic Fuel Benchmark, Oak Ridge National Lab. (ORNL), Oak Ridge, TN (United States), Oak Ridge, TN, 2019.

[5] I. Greenquist, K.M. Cunningham, J. Hu, J.J. Powers, A Metallic Fuel Performance Benchmark Problem Based on the IFR-1 Experiment, Oak Ridge National Lab. (ORNL), Oak Ridge, TN (United States), 2020. https://doi.org/10.2172/1649204.

[6] I. Greenquist, K.M. Cunningham, J. Hu, J.J. Powers, D.C. Crawford, Development of a U-19Pu-10Zr fuel performance benchmark case based on the IFR-1 experiment, J. Nucl. Mater. 553 (2021) 152997. https://doi.org/10.1016/j.jnucmat.2021.152997.

[7] I. Greenquist, J. (ORCID:0000000336533880) Powers, Metallic Fuel Benchmark Simulations Based on the X430 Experiments, Oak Ridge National Lab. (ORNL), Oak Ridge, TN (United States), 2020. https://doi.org/10.2172/1649124.

[8] I. Greenquist, J.J. Powers, 25-Pin metallic fuel performance benchmark case based on the EBR-II X430 experiments series, J. Nucl. Mater. 556 (2021) 153211. https://doi.org/10.1016/j.jnucmat.2021.153211.

[9] J. Hirschhorn, J. Powers, Assessment of the BISON Metallic Fuel Performance Models, 2021. https://doi.org/10.2172/1763469.

[10]H. Tsai, L.A. Neimark, M.C. Billone, R.M. Fryer, J.F. Koenig, W.K. Lehto, D.J. Malloy, Test Design Description (TDD). Volume 1A. Design description and safety analysis for IFR-1 metal fuels irradiation test in FFTF, Argonne National Lab. (ANL), Argonne, IL (United States), 1986. https://doi.org/10.2172/711873.

[11]N.E. Dodds, Test design description. Volume 1B. IFR-1 metal fuel irradiation (AK-181), Argonne National Lab. (ANL), Argonne, IL (United States), 1986. https://doi.org/10.2172/712141.

[12]N.E. Dodds, Test design description Volume 2, Part 1. IFR-1 metal fuel irradiation test (AK-181) element as-built data, Argonne National Lab. (ANL), Argonne, IL (United States), 1986. https://doi.org/10.2172/712348.

[13]H. Tsai, L.A. Neimark, Irradiation performance of full-length metallic IFR fuels, Argonne National Lab., 1992. http://inis.iaea.org/Search/search.aspx?orig_q=RN:24019637 (accessed December 5, 2019).

[14]D.L. Porter, H. Tsai, Full-length Metallic Fast Reactor Fuel Pin Test in FFTF (IFR-1), Idaho National Laboratory (INL), Idaho Falls, ID, 2011. 
[15]D.L. Porter, H. Tsai, Full-length $\mathrm{U}-\mathrm{xPu}-10 \mathrm{Zr}(\mathrm{x}=0,8,19 \mathrm{wt} . \%)$ fast reactor fuel test in FFTF, J. Nucl. Mater. 427 (2012) 46-57. https://doi.org/10.1016/j.jnucmat.2012.03.047.

[16]J.D. Hales, R.L. Williamson, S.R. Novascone, G. Pastore, B.W. Spencer, D.S. Stafford, K.A. Gamble, D.M. Perez, W. Liu, BISON Theory Manual The Equations behind Nuclear Fuel Analysis, Idaho National Lab. (INL), Idaho Falls, ID (United States), 2016. https://doi.org/10.2172/1374503.

[17]D. Gaston, C. Newman, G. Hansen, D. Lebrun-Grandié, MOOSE: A parallel computational framework for coupled systems of nonlinear equations, Nucl. Eng. Des. 239 (2009) 1768-1778. https://doi.org/10.1016/j.nucengdes.2009.05.021.

[18]G.L. Hofman, M.C. Billone, J.F. Koenig, J.M. Kramer, J.D.B. Lambert, L. Leibowitz, Y. Orechwa, D.R. Pedersen, D.L. Porter, H. Tsai, A.E. Wright, Metallic Fuels Handbook, Argonne National Lab., 1989.

[19]J.A. Hirschhorn, Establishing BISON Repositories at Oak Ridge National Laboratory for the Versatile Test Reactor Project, Oak Ridge National Laboratory, Oak Ridge, Tennessee, 2021.

[20]D.C. Montgomery, G.C. Runger, Applied Statistics and Probability for Engineers, John Wiley \& Sons, 2010.

[21]I. Greenquist, J. Hu, J.J. Powers, Sensitivity and uncertainty Analysis of Preliminary VTR Driver Fuel Thermomechanics Using BISON, Oak Ridge National Laboratory, Oak Ridge, Tennessee, 2021.

[22]M.H. Kalos, P.A. Whitlock, Monte Carlo Methods, 2nd ed., Wiley VHC, 2008.

https://www.amazon.com/Monte-Carlo-Methods-Malvin-

$\mathrm{Kalos} / \mathrm{dp} / 352740760 \mathrm{X} / \mathrm{ref}=\mathrm{sr}$ 1_3? $=$ =books\&ie=UTF8\&qid=1531240923\&sr=1-

$3 \&$ keywords $=$ monte + carlo + methods (accessed July 10, 2018).

[23]S.C. (ORCID:0000000301337126) Middlemas, D.E. (ORCID:0000000232121558) Janney, Current revision of the Metallic Fuels Handbook summarizing properties of fresh fuels, Idaho National Lab. (INL), Idaho Falls, ID (United States), 2020. https://www.osti.gov/biblio/1634836-current-revisionmetallic-fuels-handbook-summarizing-properties-fresh-fuels (accessed February 17, 2021).

[24]A. Withop, B.A. Hutchins, G.C. Martin, Analytical Procedures and Applications of Fluence Determinations from EBR-II Flux Wires, General Electric, Sunnyvale, California, 1969. https://www.osti.gov/servlets/purl/4753572 (accessed February 3, 2021).

[25]Fast Flux Test Facility. Conceptual System Design Descritption for the Reactor Core System, No. 31, United State Department of Energy, 1969. https://doi.org/10.2172/4145716.

[26] Weather WX Inc., Arco ID Climate Averages, Monthly Weather Conditions, WeatherWX.Com. (n.d.). https://www.weatherwx.com/hazardoutlook/id/arco.html (accessed August 31, 2021).

[27]Nuclear Systems Materials Handbook: Volume 2 - Supporting Documentation for Design Data - Rev. 37, Oak Ridge National Laboratory, Oak Ridge, Tennessee, 1988.

[28]L. Leibowitz, R.A. Blomquist, Thermal conductivity and thermal expansion of stainless steels D9 and HT9, Int. J. Thermophys. 9 (1988) 873-883. https://doi.org/10.1007/BF00503252.

[29]A.L. Pitner, B.C. Gneiting, F.E. Bard, Irradiation Performance of Fast Flux Test Facility Drivers Using D9 Alloy, Nucl. Technol. 112 (1995) 194-203. https://doi.org/10.13182/NT95-A35173.

[30]R. Sher, C. Beck, Fission-Energy Release for 16 Fissioning Nuclides, Stanford University, Standford, California, 1981. https://www.osti.gov/servlets/purl/6614291 (accessed February 2, 2021).

[31]T. Ogata, T. Yokoo, Development and Validation of ALFUS: An Irradiation Behavior Analysis Code for Metallic Fast Reactor Fuels, Nucl. Technol. 128 (1999) 113-123. https://doi.org/10.13182/NT99-A3018.

[32] G.L. Hofman, L.C. Walters, T.H. Bauer, Metallic Fast Reactor Fuels, Prog. Nucl. Energy. 31 (1997) 83-110.

[33]J.K. Fink, L. Leibowitz, Thermodynamic and transport properties of sodium liquid and vapor, 1995. https://doi.org/10.2172/94649.

[34]D.R. Olander, Fundamental aspects of nuclear reactor fuel elements, California Univ., Berkeley (USA). Dept. of Nuclear Engineering, 1976. https://doi.org/10.2172/7343826. 
[35]J.K. Shultis, R.E. Faw, Fundamentals of Nuclear Science and Engineering, Second Edition, CRC Press, Boca Raton, Florida, 2008.

[36]W.S. Yang, A.M. Yacout, Assessment of the SE2-ANL code using EBR-II temperature measurements, Argonne National Lab., IL (United States), 1995. https://www.osti.gov/biblio/78595 (accessed November 25, 2020).

[37]L. Capriotti, J. Harp, Status PIE Report on Legacy EBR-II and FFTF Metallic Fuel Experiments, Idaho National Lab. (INL), Idaho Falls, ID (United States), 2019. https://www.osti.gov/biblio/1604754 (accessed June 23, 2020).

[38]L. Capriotti, G.L. Beausoleil, Postirradiation Examination Plan for AFC-FAST Irradiation Experiment, Idaho National Laboratory, Idaho Falls, Idaho, 2019.

[39]J.A. Hirschhorn, J.J. Powers, A Plan for Benchmarking the BISON Fuel Performance Code for Versatile Test Reactor Driver Fuel Analyses, Oak Ridge National Laboratory, Oak Ridge, Tennessee, 2021. 